\title{
Shifting Confidence in Homeownership: The Great Recession
}

\author{
Anat Bracha and Julian C. Jamison
}

\begin{abstract}
:
The authors study the responses to several questions related to real estate that were added to the Michigan Survey of Consumers in July and August 2011. In particular, they asked about attitudes toward renting versus buying a home, about commuting, and about how much to spend on a mortgage. By matching the results to data (at the ZIP-code level) about relative house price declines during the recent crisis, they can study the relationship between the U.S. housing crash and the attitudes of individual consumers. They find that younger respondents are relatively less confident about homeownership after larger price declines, while older respondents are relatively more confident. In both cases, this is observed only for those with direct experience of loss (via themselves or someone close) during the crash. They find no effect on attitudes towards commuting, and they find that people who live in the high-decline areas believe it is appropriate to spend more on a mortgage.
\end{abstract}

\section{JEL Classifications: R21, E32, D12, D03, D83}

Anat Bracha is an economist in the research department at the Federal Reserve Bank of Boston. Her e-mail address is anat.bracha@bos.frb.org. Julian C. Jamison is a senior economist at the Federal Reserve Bank of Boston. His e-mail address is julian.jamison@bos.frb.org.

The authors thank Mary Burke, Stefan Nagel, Antonio Spilimbergo, and participants at the Federal Reserve Bank of Boston research seminar for helpful comments, and especially Chris Foote for advice and feedback. They also thank Michael Smith and Lynn Conell-Price for excellent research assistance throughout the project. They thank the University of Michigan, CoreLogic, and Lender Processing Services for data collection. All remaining errors are theirs alone.

This paper presents preliminary analysis and results intended to stimulate discussion and critical comment. The views expressed herein are those of the authors and do not indicate concurrence by the Federal Reserve Bank of Boston, or by the principals of the Board of Governors, or the Federal Reserve System.

This paper, which may be revised, is available on the web site of the Federal Reserve Bank of Boston at http://www.bostonfed.org/economic/ppdp/index.htm.

This version: June 26, 2012 
"A setback to confidence means a setback to the recovery of the housing market." Doug Duncan, chief economist at Fannie Mae ${ }^{1}$

\section{Introduction}

During the Great Recession, American households saw the value of residential real estate fall by over $\$ 4$ trillion in 2007 and 2008; this loss was in addition to an approximately $\$ 8$ trillion decline in the total value of U.S. stocks in 2008 alone. In spite of this massive fall in home values, a Pew Research Center survey of over 2,000 U.S. adults in March $2011^{2}$ found, surprisingly, that 37 percent still strongly agreed that "buying a home is the best long-term investment a person can make" (and an even larger percentage of respondents indicated weak agreement with the statement). Moreover, although homeownership has fallen since the crisis, it is nevertheless remarkably stable: the homeownership rate fell from 69.2 percent at its apex in mid-2004 to 66.5 percent at the end of 2010 (see Starobin 2011). Given the drop in real estate values, the persistent belief in the value of homeownership seems to reflect attitudes that go beyond financial rationales. This hypothesis is supported by the finding that 37 percent of those surveyed think being able to own a home is an "extremely important long-term financial goal," greater than the percentage who said the same for being able to live comfortably in retirement (35 percent) or being able to pay for their children's college education (31 percent). For better or worse, owning a home remains both a long-term driver of the U.S. economy and an important psychological benchmark for many citizens. Hence, it is important to understand whether and how the recent crisis has affected beliefs related to homeownership.

In this paper we examine the relationship between the real estate crisis and individual beliefs and attitudes toward homeownership. There is good reason to suspect that the crisis affected such beliefs: previous work has shown that macroeconomic shocks at various ages can affect portfolio choice (Malmendier and Nagel 2011), as well as attitudes regarding the role of government and even the degree of personal agency in determining success (Giuliano and

\footnotetext{
${ }^{1}$ Quoted in Panchuk(2011).

${ }^{2}$ See Taylor et al. (2011).
} 
Spilimbergo 2009). Other work has studied the relationship between exposure to stressors, such as violent conflict, and underlying economic preferences like risk aversion (for example, Voors et al. forthcoming). All of this literature finds that macroeconomic shocks have significant individual-level consequences, albeit along varying dimensions, leading to the supposition that we may currently be seeing the consequences of an analogous and potentially long-lasting shift in attitudes.

Following previous research, we also give special attention to the effect of exposure on the magnitude of any attitude changes, where exposure is measured along two separate dimensions: age (existing evidence suggests that beliefs are most malleable in younger people) and the level of direct experience with the crisis. We are able to proxy the latter dimension of exposure by asking individuals if they or someone they know was foreclosed upon or lost a significant amount of money in the housing crash. From here on we will refer to individuals who experienced such a financial loss themselves or via someone close to them as having experience and to individuals who did not have this type of experience as having information only. Note that the latter category describes individuals who had access to information about the crisis both through the media and social interaction but were not as intimately personally exposed to the precipitous declines in price. In our analysis we explore whether this level of exposure (through information only or also with more direct personal experience) affected any changes in beliefs regarding the housing market.

Whereas previous papers have mostly looked at variation over time in order to ascertain the link between aggregate shocks and individual beliefs, we instead use variation over space. In particular, we are able to combine several datasets to match ZIP-code level declines in housing prices (and foreclosures) with responses to questions that were added to the monthly Michigan Survey of Consumers. Our main outcome variable asks people whether and how strongly they believe that owning a home is better financially than renting a home. ${ }^{3}$ Other outcome variables include asking the maximum amount that should be paid toward a mortgage, the relative

\footnotetext{
${ }^{3}$ Other work has focused on the discrepancy between beliefs after the crisis about buying versus selling homes (e.g. Englehardt 2011) but we will restrict our focus here to attitudes towards homeowning in general.
} 
willingness to commute, and general risk aversion via a standard (hypothetical) investment decision.

Our main results are as follows. People who in 2008 lived in ZIP codes that were hardest hit by the crash in housing prices-as compared to those who resided in areas that were least severely affected-are significantly more likely to be confident about owning a home if they are older (above 58 years old in our sample), but are significantly less likely to be confident about owning a home if they are younger. These results control for demographics, current absolute house price levels, and other factors, but importantly are concentrated in the approximately one-third of our sample who report that either they or someone close to them actually lost a large amount of money in real estate during the crisis, that is, those with first- or second-hand experience of the housing crash rather than those who watched it from the sidelines (information only). We argue that the latter result implies that merely possessing information about an adverse event is not enough to change behavior-rather, something like direct experience is required to change an individual's confidence in homeownership. This different response is because presumably almost everyone in the United States was exposed to multiple media headlines about what had happened to the housing markets in their neighborhood and around the country, and yet people who did not personally suffer a loss from the housing crash or know someone close to them who did, do not show a similar divergence in confidence.

In terms of the striking age differential, one possibility is that relatively younger respondents were indeed more malleable in terms of their outlook, and hence they internalized the sharp drop in housing prices as a regime change. In the new perceived regime, housing is a risky investment and thus (relatively) to be eschewed. Available evidence from economics and psychology further suggests that such a perceptual change is likely to be persistent. On the other hand, older respondents, whose models of the world are harder to alter, see the drop in house prices as a temporary dip in a stable, long-term, upward trend, making the current downturn a particularly good time to purchase. Of course, it is also possible that older consumers buy homes more for consumption and less for investment, although the question was explicitly worded to isolate general beliefs and not to focus on individual circumstances. 
There is, clearly, a potential endogeneity issue here: we believe that the differences in attitudes are due to the declines in real estate prices and not to other characteristics of those particular ZIP codes (which could have led to both), but we lack survey data predating the crisis to prove this connection. That being said, there are no significant correlations (across ZIP codes) between house price declines and various relevant observable individual characteristics. In particular, there is no link between the size of the fall and any of the following: average age, income, risk aversion, or homeownership rate. This initial identification, along with the bifurcating nature of the result across age groups (which would be difficult to explain with preexisting differences), suggests that the reason for the currently existing variation is indeed the crash itself. However, as in most of this literature, we cannot completely rule out the possibility of an alternative explanation.

For mortgage spending, an analogous regression shows that there is a positive link between aggregate house price decline and a willingness to commit a larger percentage of income to a mortgage. This relationship is economically and statistically significant overall and for younger respondents, but not for older individuals on their own. There is perhaps a greater danger of reverse causality here than for confidence in homeownership, since a natural story is that spending more on mortgages is more likely to lead to a bubble and resulting crash. We are therefore hesitant to push this result as far. Meanwhile, we find no main effect on either willingness to commute or general risk attitudes, as the latter result weakly suggests that there was no spillover from attitudes toward housing to attitudes in other specific domains.

We proceed by reviewing two strands of recent results: first, what is known about the effects of financial crises and other stressors on individual beliefs, and, second, some specifics regarding housing attitudes and the overall environment of the Great Recession. After that, we describe our data sources in more detail, including relevant summary statistics. The heart of the paper outlines our empirical approach and reports the key regression results. Finally, we conclude and discuss the results in more detail, including possible policy implications. 


\section{Literature Review}

We are interested in examining whether the recent crisis had an effect on individuals' preferences and potentially on their future behavior. The approach we take involves analyzing survey data across geographic locations that differ in their crisis experience. Hence, there are several distinct but equally relevant strands of the literature. First, going through a crisis (with potential concomitant loss of wealth, employment, and so on) may naturally lead to a negative affective state. Therefore, we examine studies looking at the effect of emotional reactions, in particular due to a negative experience, on economic decisionmaking. We then turn to field papers that study adverse personal experiences, and indeed disasters more generally, and their implications for response to, for example, uncertainty. Third, since we are interested in the relationship between the real estate crash (which, along with the financial crisis, was a hallmark of the Great Recession) and individual beliefs, we report studies that examine, albeit using slightly different empirical strategies, the effect of previous financial events on attitudes and economic decisionmaking. Finally, we report three studies looking at the relationship between the recent real estate crisis and self-reported individual outcomes.

It has long been known to psychologists that affective states such as emotions and confidence can impact decisionmaking, including attitudes toward risk and other decisions that are quantitatively important to the economy. In our context a classic paper by Lerner and Keltner (2001) is relevant: they show that fear and anger, emotional states that are likely to manifest while experiencing a negative event, such as a recession, have an effect on risk-taking in a heterogeneous manner. They find that fear is associated with a reduced sense of control and greater risk aversion, whereas anger is associated with active agency, optimism, and relatively more risk-seeking behavior.

However, not all experiences influence attitudes and beliefs equally. In an early comprehensive review of the psychological literature on exposure to traumatic situations, Weinstein (1989) concludes that having first-hand experience of dangerous situations (such as crime and natural hazards) disproportionately leads to behavioral change, although the effect 
does not appear in every situation (for example, vehicular accidents do not seem to induce greater seatbelt utilization). In economics, Simonsohn et al. (2008) perform a laboratory experiment and find that people are influenced more by those who they actually interact with than by those who they simply observe. This work is what prompted us to include a measure of individual-level exposure to the housing crash. Although these previous studies are not concerned with financial crises, they suggest that different levels of experience with an economic crash may have differential effects on beliefs and behavior.

Exogenous external stressors of many types have been found to be relevant for shaping preferences: for example Nunn and Wantchekon (2009) conclude, somewhat controversially, that modern Africans whose ancestors were more heavily raided in the slave trade are now less trusting toward both their neighbors and their governments and institutions. Similarly, focusing on social preferences, Eckel, DeOliveria, and Grossman (2007) find a relationship between exposure to Hurricane Katrina and later charitable giving, including a potentially unexpected reversal in which those more closely affected by the hurricane actually give less when primed to recall the events of that period. This may be due to overstimulation or reduced sensitivity to adverse outcomes.

Along similar lines, one recent paper stands out as relevant to the current study. Voors et al. (forthcoming) look at the causal impact of violent conflict in Burundi on risk, time, and social preferences. Using geographic variation in exposure to violence, as we do, and fairly convincingly controlling for possible endogeneity issues using instrumental variables and other methods, they find that the stress of exposure to violence leads to substantially less risk aversion, in addition to more impatience and more prosociality; the latter, perhaps surprising, result actually matches previous literature (for example, Bellows and Miguel 2006), but the risk and time dimensions are novel here. Voors et al. conclude that "Adverse, but temporary, shocks can thus alter savings and investment decisions, and potentially have long-run consequences."

Turning to financial crises specifically, analogous mechanisms appear to be at work despite the milder immediate consequences. Nishiyama (2006) finds more risk aversion on the part of 
financial institutions in the United States and (weakly) in Asia following the 1997 Asian crisis, although direct causality is difficult to tease out. Mudd. Pasheve, and Valev (2010) use survey data to study the effects of the 1996 Bulgarian banking crisis. They find that individuals who self-report having lost money in the crisis are more pessimistic about future crises, and indeed are more likely (for instance, during the global crisis in 2009) to withdraw their savings from financial institutions. Likewise, Osili and Paulson (2009) study immigrants to the United States and find that those who came from countries that experienced banking crises have a higher probability of being currently unbanked in the United States, an effect that is attenuated by time spent in this country (that is, experience with relative stability). As Mudd, Pashev, and Valev (2010) and our results report (thus confirming the psychological evidence above), exposure to the pertinent crisis through personal experience has a larger effect on behavior than information only.

Closely related are two recent papers that look at the effects of macroeconomic cycles in the United States on attitudes of investors and consumers. Giuliano and Spilimbergo (2009) create a dummy variable to capture whether regional GDP growth (in the region where individuals lived when 16 years old) was worse than -3.8 percent for at least one year in various stages of life. They find the strongest effect for the formative stage, namely, ages 18-25 years; we find this result is especially interesting, as it means that such impacts are long lasting. Their outcome variables are psychosocial measures taken from the General Social Survey (GSS). The results are that experiencing a recession when one is between 18 and 25 years of age leads to a greater belief that success is attributable to luck rather than to skill, with a corresponding greater desire for government intervention but a simultaneous lower level of confidence in government as an institution. Giuliano and Spilimbergo control for demographic measures and use an identification strategy that exploits differences in experience across both time and geographic region. However, like us, they do not have panel data to test these predictions.

The other paper that most closely inspired the current study is Malmendier and Nagel (2011), which looks at interactions with the stock market (see also Malmendier and Nagel 2009 for a similar study regarding inflation). They ask whether people who have experienced lower 
returns on equity investments over the course of their life behave differently when making financial choices. Using an empirical strategy that exploits variation over time in U.S. stock market returns (and therefore also across cohorts of individual investors), they indeed find that economic hardship has an effect on economic behavior: those with worse experiences are less likely to participate in the stock market and are more likely to hold fewer stocks within their portfolio, even conditional on stock market participation. As in our results, Malmendier and Nagel (2009) find a stronger negative effect for younger individuals, although they study the accumulated experience of a lifetime rather than a single crisis event. Note that they do not actually observe individual-level experience with stock returns, only aggregate returns at the relevant time.

Turning to the real estate crisis in particular, Guiso, Sapienza, and Zingales (2011) study strategic default, defined as default for reasons other than direct liquidity issues (most commonly relating to "underwater" mortgages, although that is not a necessary condition in their formulation). Using survey data (not actual defaults), they find that the probability of strategic default decreases according to the level of trust in financial institutions but increases according to the level of anger regarding their situation, paralleling the original Lerner and Keltner (2001) results. Relevantly for the present study, they also find that default-prone individuals do not tend to cluster at the ZIP-code level (strengthening it as a unit of analysis) and that the absolute level of real estate prices is less predictive of default than is the relative decline in prices.

Finally, two papers examine the effects of foreclosures during and following the recent housing crash. Molloy and Shan (2011) look at individuals who have recently suffered foreclosure, finding less access to credit, fewer mortgages, and lower rates of owner-occupied housing for that group (nonrandomly selected, by construction). On the other hand, those individuals do not appear to have defrayed housing consumption by, for example, moving in with family or to lower-quality neighborhoods. Collins and Choi (2010) study attitudes toward housing in August 2008, toward the end of the real estate crash. They find that higher foreclosure rates (at the ZIP-code level) correspond to more pessimistic beliefs regarding the 
risks of homeownership, which is not surprising and roughly matches our results for younger individuals (their sample was restricted to individuals under 65 years of age). However, unlike us, they do not find a link between housing price declines in the previous year and beliefs concerning homeownership. This is possibly due to the restricted time period of their house price data (which is culled from Zillow.com), or possibly to the nonrepresentative nature of their Internet survey sample: under 65 years of age, income under $\$ 75,000$ per year, and, most importantly, only residing in the nine-county San Francisco Bay Area. Collins and Choi control for basic demographic characteristics but they have only aggregate foreclosure rates, and are unable to distinguish between direct and indirect experience with the housing shock and financial crisis, which we found to be an important mediator in the formation of individual attitudes.

\section{Data}

To investigate the effects of the Great Recession-in particular, the crisis in the housing market - on attitudes towards risk and investment in real estate, we surveyed 986 individuals aged 18 to 95 years old using the Michigan Survey of Consumers. This is a telephone survey that is nationally representative of households that have a landline. We designed seven questions that the University of Michigan added to their standard consumer survey. In these questions we asked respondents about: (1) their ZIP code as of late 2008, (2) their current ZIP code, (3) their opinion on whether buying or renting is better financially, (4) whether they or someone close to them was foreclosed on or suffered a large loss in the real estate market, (5) whether they would be willing to increase their commute to reduce housing expenses, (6) how much they think is reasonable to pay on a mortgage given a certain income, and (7) a hypothetical investment decision to measure risk attitude. These additional questions were included in the July and August 2011 surveys and posed to all survey respondents. We also use a subset of the standard Michigan consumer survey, including demographic information at the individual level on age, gender, race, education level, income category, and homeownership to control for individual characteristics. A list of the variables we use is provided in the appendix (see Table A1). 
The novel contribution of our data is the use of current and 2008 ZIP codes to match each individual's survey responses with the real estate market conditions in his or her residential location. ${ }^{4}$ Collecting both current and 2008 ZIP codes enables us to distinguish the effect of more recent real estate market conditions from the effect of the conditions at the peak of the financial crisis. The real estate data we use are the CoreLogic Home Price Index (HPI) and Lender Processing Services (LPS) data on loans processed and the percentage of loans that are delinquent or foreclosed upon, all at the ZIP-code level. The HPI is a repeat-sales index which is normalized to 100 for the month of January 2000. That is, the levels are comparable over time within a ZIP code, but are not comparable across ZIP codes. We will be interested primarily in changes in the HPI, which are all fully comparable, since the geographic scaling factor is the same at each point in time.

We compiled HPI data for each month between January 2001 and May 2011, and calculated the seven-month moving average for each month. This is a simple average of the HPI over the seven-month period that includes the month of interest and the three preceding and three following months. ${ }^{5}$ Then by finding the month in which the HPI moving average was at its peak and the month in which the HPI was at its lowest level after the peak, we calculated the greatest drop in the HPI for a given location. Note that the CoreLogic data are limited to 6,521 ZIP codes. Hence, we imputed HPI data for the remaining ZIP codes by using city HPI averages. If using a city average was not possible, we used the county HPI average, and if using a county average was also not possible, we used the state average HPI. We did not have this problem with delinquency data, which are available for all ZIP codes. We collected delinquency data for two months per year-May and October-from 2006 to 2011 (excluding October 2011, as the data were not yet available).

\footnotetext{
${ }^{4}$ Due to privacy restrictions, we were not able to get the ZIP code data along with the other survey responses. Hence, we constructed the dataset in two steps: first, the Michigan Survey of Consumers sent us a file with the ZIP code responses only; we sent them back the file of ZIP code responses merged with the local economic data (described in full in this section). In the second step, the Michigan Survey of Consumers sent us back a full dataset of the survey responses, which did not contain the ZIP codes but did have the economic data merged by ZIP code.

${ }^{5}$ The reason for the moving average is that the HPI dataset has only a few sales observations per ZIP code per month, so the raw data are quite noisy and potentially quite unrepresentative.
} 
In addition to real estate market information, we used gas and food price information for each location. Gas prices were taken from the U.S. Energy Information Administration and are computed at the state level. We used gas prices on a monthly basis for 2001-2011, and for each month we computed a seven-month moving average (that is, the average price over a sevenmonth period including three months preceding and three months following a given month). Food prices (whole and 2 percent milk; grain bread, rolls, rice, pasta, and cereal; and fresh and frozen regular fat meat) were taken from the U.S. Department of Agriculture and are given quarterly at the "market group level," which we link to a Federal Information Processing Standards (FIPS) code using a conversion chart, and then match with ZIP codes. With food prices, as with HPI and gas prices, we computed a seven-month moving average and then found the month in which the moving average was at its peak and the month when it reached a post-peak minimum. Lastly, we used data from the 2000 U.S. Census on neighborhood characteristics, including gender composition, racial composition, poverty percentages, and the percentage of residents with a college degree in a given ZIP code.

The vast majority of respondents gave their ZIP codes for both 2008 and 2011: only 18 people out of 986 did not supply this information in full. However, those respondents who could not provide ZIP codes were asked their city and state. We then matched the responses of these individuals to the average HPI, delinquency, food and gas price data (these are roughly countylevel data) associated with their FIPS code, if they reported their city. If they did not report their city, we supplemented their data with the average data for their state. After this process, we were left with six respondents to whom we could not match any geographic real estate and price data.

The respondents' median age in our sample is 57 years old, with 82.9 percent white, 8.7 percent black, 4.5 percent Hispanic, 2.7 percent Asian, and 1.0 percent Native American. The median highest grade completed is 14 , the median income category is $\$ 50,000-\$ 59,999,57.6$ percent of the sample is female, and 83.4 percent of respondents are homeowners. The distributions are provided in figure 1. 
Figure 1: Summary Statistics
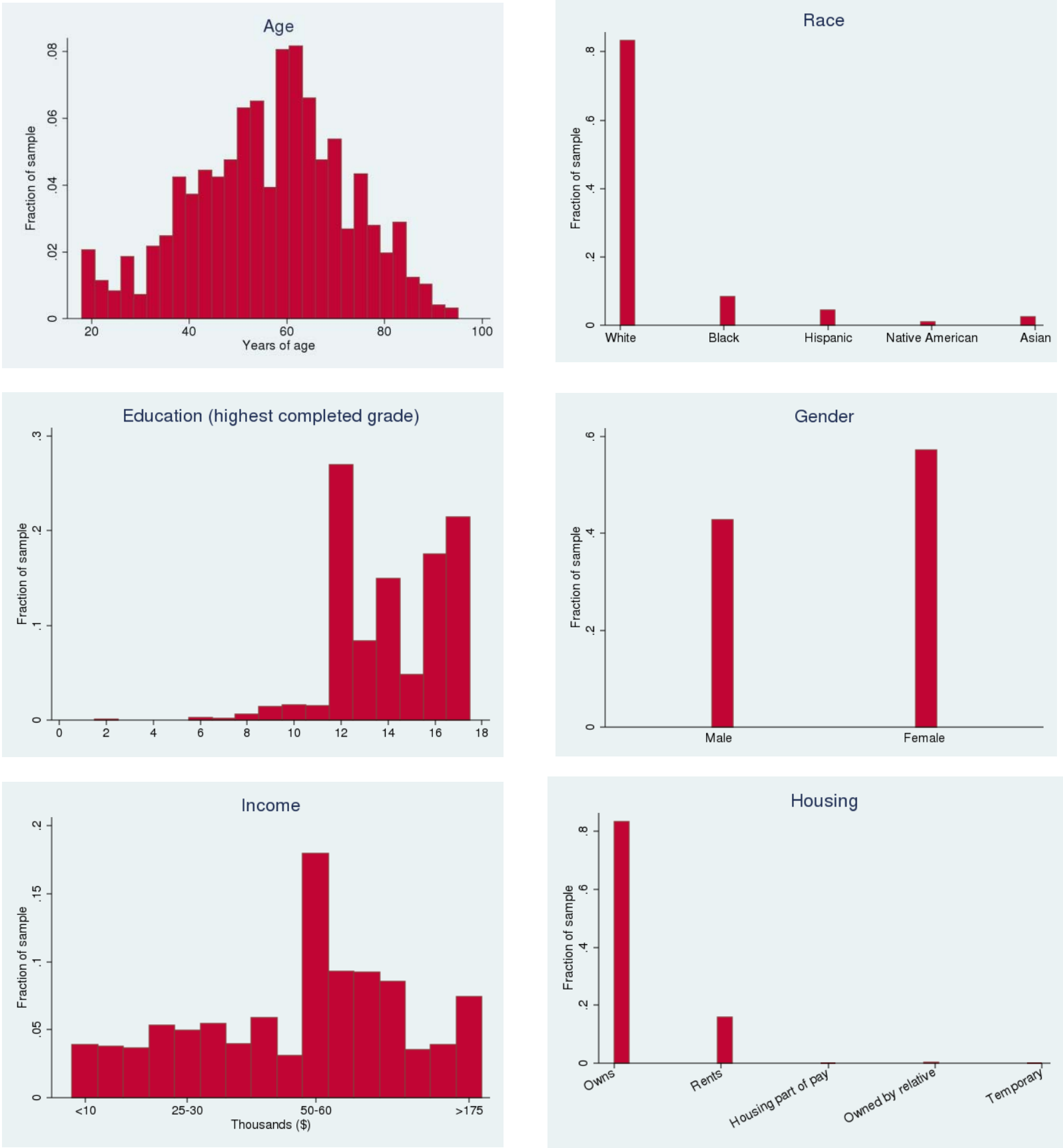

Source: Authors' calculations. 


\section{Results}

\subsection{Overall Outlook}

The standard Michigan consumer survey includes questions on the general state of the economy and on the perception of key variables such as inflation and unemployment.

The question addressing the overall state of the U.S. economy is worded: "A year from now, do you expect that in the country as a whole business conditions will be better, or worse than they are at present, or just about the same?" The five possible responses are (1) better a year from now, (2) about the same, (3) worse a year from now, (4) don't know, and (5) not available.

Regarding inflation, respondents are asked: “During the next 12 months, do you think that prices in general will go up, or go down, or stay where they are now? Do you mean that prices will go up at the same rate as now, or that prices in general will not go up during the next 12 months?" The possible answers here are: (1) go up, (2) go up (at same rate), (3) will not go up, (4) go down, (5) don't know, and (6) not available. Both of these questions are also posed with

respect to the respondent's opinion on the expected state of the economy and inflation five years from now. These questions allow us to look at the economy's prospects, as people perceive them, in both the short run and the long run.

We find that 49 percent of our sample think that the U.S. economic situation will remain unchanged in the short run (one year), but at the same time, 65 percent think that the economic situation will be worse five years from now. As for changes in the general price level, the expectation is that prices will go up both in the short run (85.66 percent think prices will go up) and in the longer run (89.19 percent). The distributions of responses are presented in figure 2 below.

The Michigan survey also provides us with respondents' expectations regarding the unemployment rate and interest rates. Unfortunately, these measures are available only for the short run. The question on unemployment asks: "How about people out of work during the coming 12 months-do you think that there will be more unemployment than now, about the same, or less?" The possible answers are (1) more unemployment, (2) about the same, and (3) 
less unemployment. We find that 49 percent think the unemployment rate will remain high but will not increase, while 36 percent believe it will increase. Only 13 percent think unemployment will improve in the short run. As for interest rates, the question asks "What do you think will happen to interest rates for borrowing money during the next 12 months-will they go up, stay the same, or go down?" The possible answers are: (1) go up, (2) stay the same, and (3) go down. We find that 52 percent of our sample thinks that rates will go up, and 92 percent think these rates will either go up or stay unchanged. Only 7 percent think rates will go down. This is not surprising, as U.S. interest rates are at a record low, but it is a good indication that the survey respondents are answering nonrandomly.

Figure 2: Macroeconomic Outlook
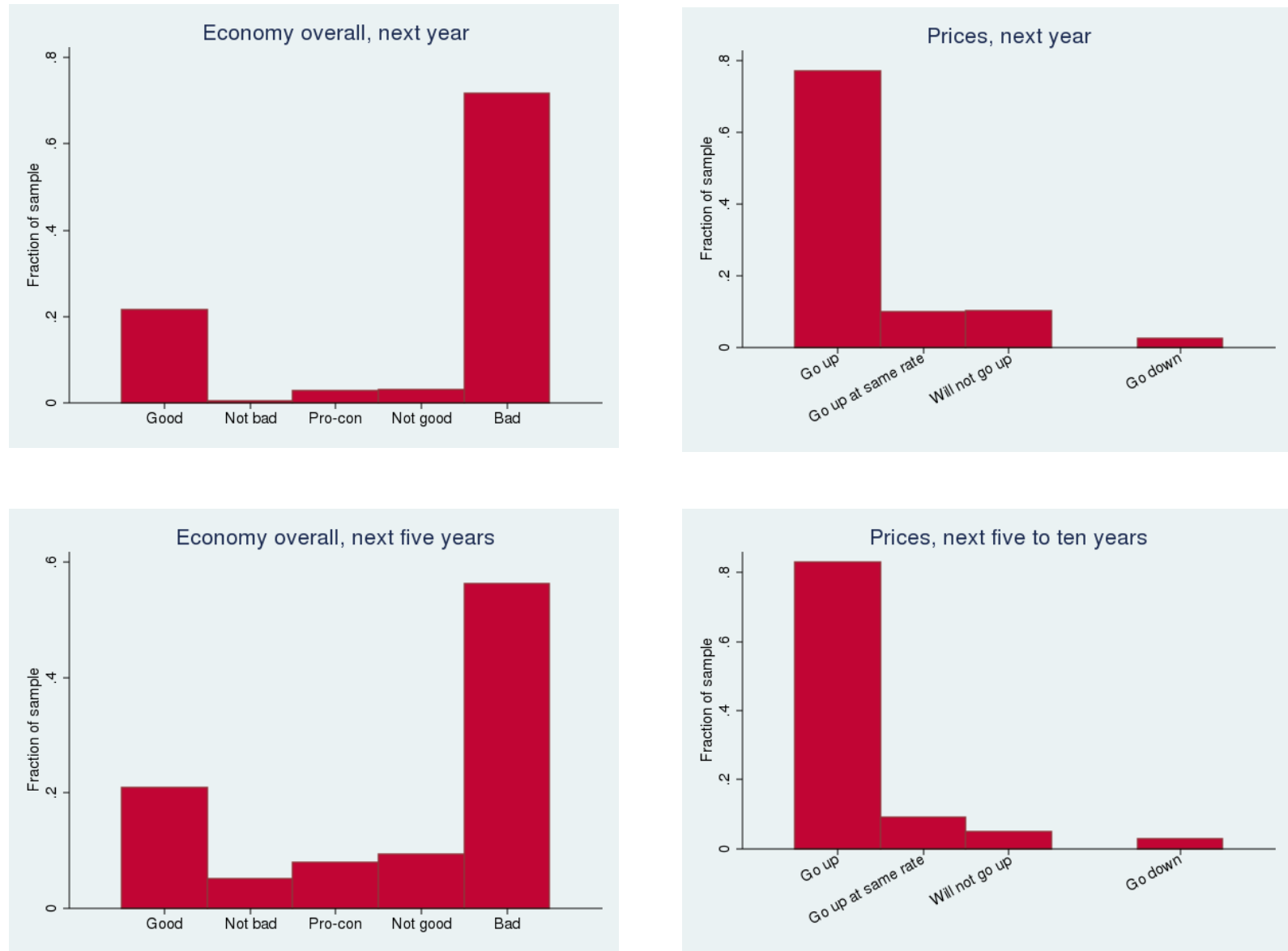

Source: Authors' calculations. 


\subsection{Residential Real Estate Market}

To examine respondents' specific attitudes toward the housing market, we added three main questions, as described earlier, to address 1) whether attitudes towards buying or renting have changed, 2) how much individuals are willing to spend on mortgages, and 3) how willing they are to increase their commute to reduce housing expenses. We cannot directly examine attitude changes over time; rather, we examine the implied effect using geographical variation for identification, since different U.S. locations varied in the severity of the real estate crash experienced before and during the Great Recession. Our aim is to determine to the extent possible whether different experiences of the housing market crash had different effects on any of these attitudes - toward owning a home, paying a mortgage, and commuting.

\subsection{Rent versus Own}

The first question of interest is whether the individuals' different experiences during the real estate market crash led to corresponding differences in their attitude towards buying a home. As mentioned, homeownership rates, although declining, are still high and Americans still consider homeownership an important long-term financial goal. Moreover, since 1960, the U.S. homeownership rate has remained stable at well over 60 percent. The rate was 62.1 percent in 1960, increasing to almost 70 percent in the mid-2000s and dropping slightly in 2010 (U.S. Bureau of the Census 2011). Hence, by their behavior over the past 50 years a majority of Americans have revealed that they think homeownership is better financially then renting. To investigate whether there has been a change in this sentiment, we asked the following question:

We are interested in your opinion about whether, financially speaking, it is better to buy a home or to rent a home. Which of the following five options best describes your opinion: 1) owning a home is without a doubt better financially than renting a home; 2) owning a home is probably better financially; 3) owning and renting a home are equally good financially; 4) renting a home is probably better financially; or 5) renting a home is without a doubt better financially than owning a home? 
In the U.S. population the homeownership rate differs by race, and is highest among whites, 74.5 percent of whom owned their home in 2010. Changes in answering this question may be especially interesting in our sample, as most of our respondents are white (82.9 percent) and thus belong to the racial group most likely to own a home. Indeed, 83.4 percent of our sample own their home-see Figure 1 above.

Examining the responses to our rent-versus-own question (see figure 3) we find that the majority of respondents think either that (1) owning a home is without a doubt better financially than renting a home, or that (2) owning a home is probably better financially. Nevertheless, there is some variation: about 20 percent answered either that the two options (renting and owning a home) are about the same, or that renting is better financially. Moreover, even the two most common answers, (1) and (2), differ on an important dimension-the confidence that people express in the assertion that buying a home is better financially. Given the historic U.S. rates of homeownership, it is not surprising that the majority of our sample expresses a preference for buying over renting. However, the choice of (2) rather than (1) reveals diminished confidence in buying a home. With their confidence shaken, it is likely that these respondents would hold back or advise others to hold back on buying a home.

To better distinguish among these responses, we isolate those that express strong confidence that homeownership is the better financial choice. We classified these strong responses as 1, and all other responses as 0 . We then examine, using a probit regression, what affects the probability that a respondent will express strong confidence in homeownership. 


\section{Figure 3: Rent versus Own}

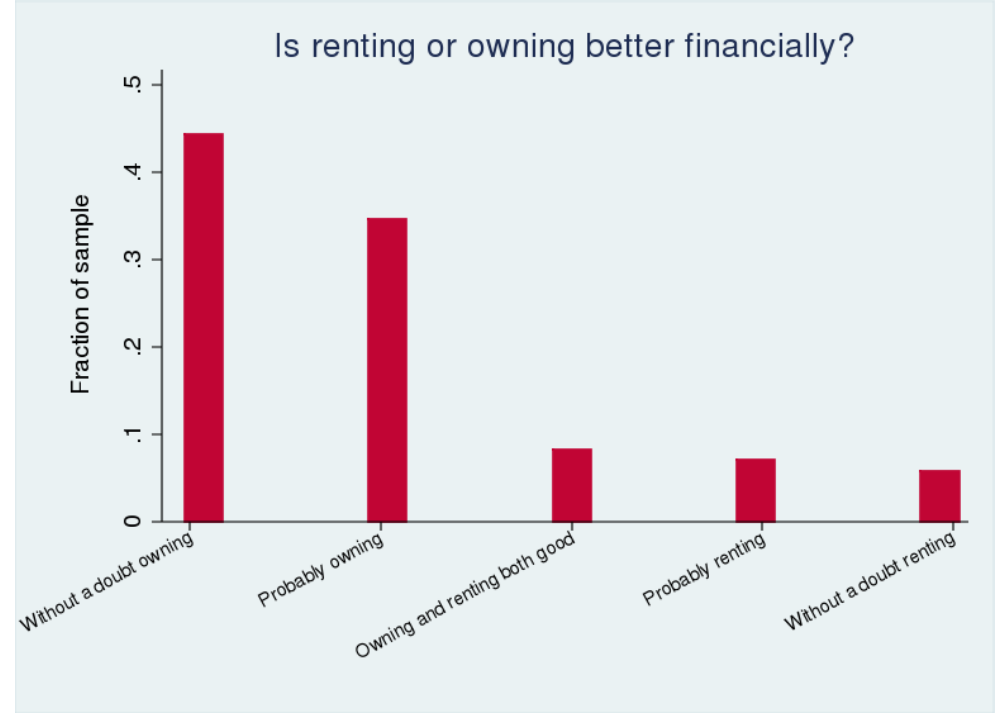

Source: Authors' calculations.

Our main focus is the relationship between the 2008 real estate crash and confidence in homeownership following this event. To examine this relationship we calculated the greatest percentage decline in the seven-month moving-average home price index (CoreLogic HPI) for a given location. Specifically, we recorded the highest HPI in a given location and then searched for the lowest HPI point after the peak. We then calculated the percentage change of this decline from the peak price. As figure 4A shows, most U.S. locations experienced a peak in the home price index between February 2005 and May 2007. Across the different ZIP codes the times at which the lowest HPI occurred after its peak are concentrated at the end of the period, in May 2011. Excluding this month, we reveal two secondary periods - mid-2009, and the time between October 2010 and April 2011-with the bulk of the lows again occurring toward the end of the period, as shown in Figure 4B. 
Figure 4: Time of Highest and Lowest Home Price Index level

(A)

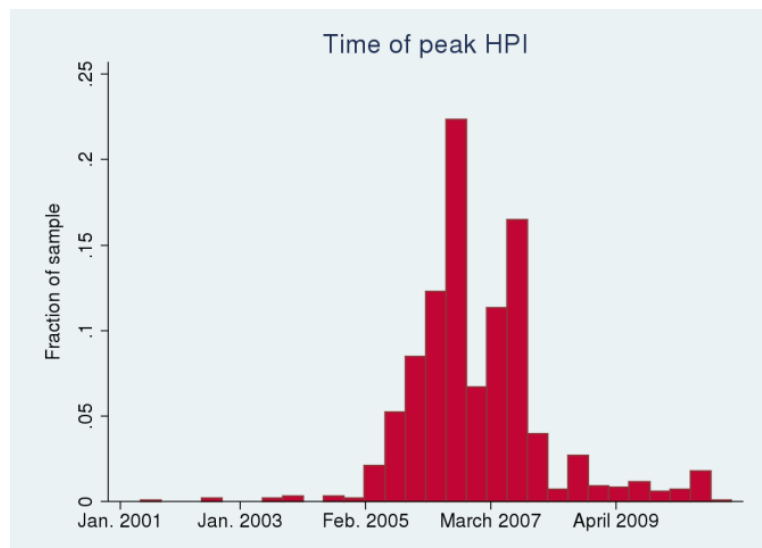

(B)

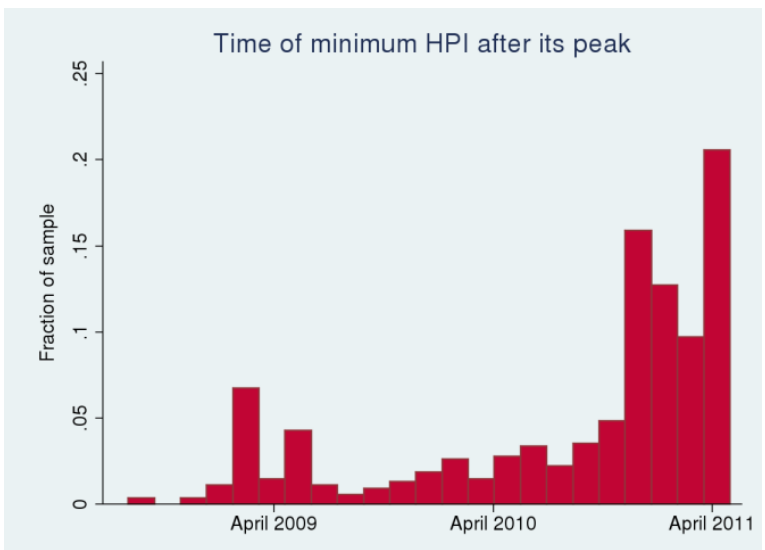

Source: Authors' calculations

Our main variable of interest is the decline in the HPI; however, there are other explanatory variables that can impact housing confidence: demographics and neighborhood characteristics, risk aversion, personal experience, and current market conditions. We control for these factors one at a time, explaining the rationale for each and then adding these variables to the previous specification so that the individual effects are clear. As the literature suggests, exposure, in terms of both age and degree of personal experience with the crisis, is likely to be important for understanding attitudes towards homeownership, and we control for these two dimensions of exposure separately. In addition to the role of age as a basic linear demographic variable, it is possible that different age groups have systematic (nonmonotonic) differences in attitudes towards homeownership, and, in particular, that younger individuals are more influenced by economic conditions. We therefore look for an age-related breakpoint in the data, and indeed we find that younger and older age groups have different attitudes towards homeownership. We perform an independent analysis of each subgroup and then conclude this subsection by presenting some robustness analysis of different response classifications.

We first regressed the rent-versus-own responses (buying is undoubtedly better as "1" versus other responses as " 0 ") on individual demographic categories, including gender, marital status, age, number of children under 18 years old, education, income bracket, race, language in 
which the survey was conducted (English or Spanish), and homeownership categories (rent, own, home owned by relative, and so on). To these regression results we added the main variable of interest - the percentage change in HPI-for the individual respondent's residential location in early 2008, just after the height of the financial crisis.

We find that, relative to married individuals, those who are separated, divorced, widowed, or never married are less confident that homeownership is better financially than renting. This is the case even after controlling for the effect of actual homeownership $\left(\beta_{\text {married }}=0.36, p<0.01\right) .{ }^{6}$ All else being equal, women are less confident about the financial benefit of buying a home than men, which may reflect gender differences in risk aversion $\left(\beta_{\text {female }}=-0.20, p<0.05\right)$. Surprisingly, we find that some lower-income groups are more confident in the financial benefits of owning a home. However, this is evident only for some of the low-income groups. Furthermore, compared with white respondents, those who identify as Hispanic have stronger confidence in homeownership, controlling for all other effects $\left(\beta_{\text {hispanic }}=0.60, p<0.05\right)$. However, respondents whose interview was conducted in Spanish, which could be an indicator of recent immigration or less-complete assimilation, were less confident in the merit of buying a home $\left(\beta_{\text {spanish }}=-1.56\right.$, $\mathrm{p}<0.01)$. This is consistent with the results of Collins and Choi (2010) who in their sample of San Francisco Bay Area residents found that having English as one's primary language has a significant positive effect on the likelihood of buying a home within one year. Lastly, as expected, those who currently rent are less confident in the benefits of buying a home than those who currently own a home $\left(\beta_{\text {rents }}=-0.60, \mathrm{p}<0.01\right)$. The results of this regression are presented in table 1, column (1). Interestingly, the percentage drop in the home price index does not seem to be related to the confidence in the financial benefit of owning a home compared to renting.

Next, we control for the neighborhood characteristics of the respondent's current (2011) community, as these may affect the respondent's inclination whether to buy a home or not. We control for gender composition, racial composition, poverty percentages, and the percentage of residents with a college degree. Unfortunately, the latest census data for these measures is from 2000. Nevertheless, since a neighborhood's demographic composition usually changes slowly,

\footnotetext{
${ }^{6}$ See section 4.4 for a discussion of the possible endogeneity of this variable.
} 
we believe that these variables are strong proxies for the residential characteristics of the respondents' current location. ${ }^{7}$ Adding neighborhood controls does not change the results; in particular, the percentage drop in the HPI remains insignificant. We do find that the more educated a neighborhood's inhabitants are, the more likely the respondents are to have less confidence in the benefit of buying a home compared with renting a home. (Note, this is the effect of the percent of the neighborhood with a college degree: $\left.\beta_{\text {percBA }}=-1.96, p<0.01\right)$. It is possible that the more educated a neighborhood's residents are, the more people are exposed to financial news, and therefore they may be more open to revising their views. The full set of results for this specification is given in table 1, column (2).

There is a growing literature investigating the factors affecting individual well-being, including a retrospective evaluation of past experiences, which may be relevant for a study such as ours that addresses the aftereffects of a severe crisis. Interestingly, the literature finds that decision utility is best described by the peak and end of the experienced utility. The motivating example for this theory was in the domain of medical procedures and pain evaluation, where it was demonstrated that an individual's retrospective evaluation of a painful experience was best described by the peak sense of pain and the pain felt at the end of the procedure (Kahneman 1999). This phenomenon is known as the "peak-end" rule, and despite its origins in the medical domain, it is thought to be a general rule that applies to various areas; indeed, it was recently argued to be important in explaining the probability that a worker will quit his or her job (Clark and Georgellis 2004). Applying this rule to the real estate market in the economic recession, the "peak" would be the greatest percentage decline in home prices and the "end" would be current prices, also measured as a change relative to some baseline. The HPI value is exactly such a measure (since it is the ratio of current prices to those of January 2000), although admittedly this baseline is somewhat arbitrary. To capture the peak-end rule as well as possible, we added the mean and standard deviation of the HPI in 2011 in the respondent's most recent (2011) residential location. As table 1 column (3) reveals, adding the end effect does not change the results.

\footnotetext{
${ }^{7}$ In our sample, only 108 of 980 respondents moved. Using the census data for the respondents' 2008 location does not affect results.
} 
Although we find no relationship between the real estate crisis and confidence in buying a home, this may be different for individuals who personally experienced the crisis-namely, those individuals who themselves suffered from the crisis or are close to someone who didcompared to individuals who were exposed through information or indirect contacts only. The idea here is that having personally suffered from the downturn in the real estate market or being close to someone who did may make the crisis more salient and thus more likely to change one's attitudes. In contrast, a person who did not experience the crisis first-hand and does not know anyone close to them who did will not place as much emphasis upon it and, as a result, will not change her attitudes.

To capture this proximity effect, we asked the following question:

Have you or has anyone close to you experienced foreclosure or lost a lot of money in the real estate market in the last five years?

We then added a dummy variable to capture the response to this question. The baseline is a "yes" response, indicating that the respondent experienced foreclosure, lost a lot of money in the real estate market, or is close to someone who did. Hence, the main effect is for those who personally experienced the housing crisis, and the dummy variable captures the differential effect on those who were exposed to the crisis through information only. We also added an interaction of this dummy variable and the percentage change in the HPI in the respondent's 2008 location. This was done to capture the potentially distinct effect that the local real estate market may have had on those who had information only, as compared to those who had experience. The results of this specification are given in table 1, column (4). As before, and whether one experienced the crisis or had information only, local real estate conditions do not seem to influence confidence in buying a home.

Lastly, it is possible that people with different risk attitudes respond differently to the rentversus-own question as a result of greater or lower risk aversion. To control for this effect, we added the responses given to our risk attitude question:

Suppose you have $\$ 10,000$ and you have the opportunity to invest in a project. Each dollar you invest in this project has a 50 percent chance to double and a 50 
percent chance that it will lose half of its value. How much of the $\$ 10,000$ would you invest in the project?

The lower the amount one is willing to invest, the more risk averse she is. Indeed, consistent with past evidence (for example, Morin and Suarez 1983), we find that older people (above the median age of 57 years in the sample) are more risk averse than the young (57-years old and below in the sample). This can be seen by comparing figure $5(\mathrm{~A})$ to figure $5(\mathrm{~B})$-about a third of the older people in the sample decided not to invest at all in the project, while less than 20 percent of the younger individuals choose not to invest. In addition, over a third of the younger individuals would invest half their money in the project, while the older individuals were less likely to do so.

Hence, we added to the regression the investment amount an individual chose, and its interaction with age. Based on this proxy for risk aversion we do not find that risk aversion has a significant effect on confidence in homeownership, and inclusion of the proxy also does not change the basic results: the percentage drop in real estate prices does not seem to be related to confidence regarding the financial benefit of owning a home versus renting one. ${ }^{8}$

\section{Figure 5: Hypothetical Investment Distribution by Age}

(A)

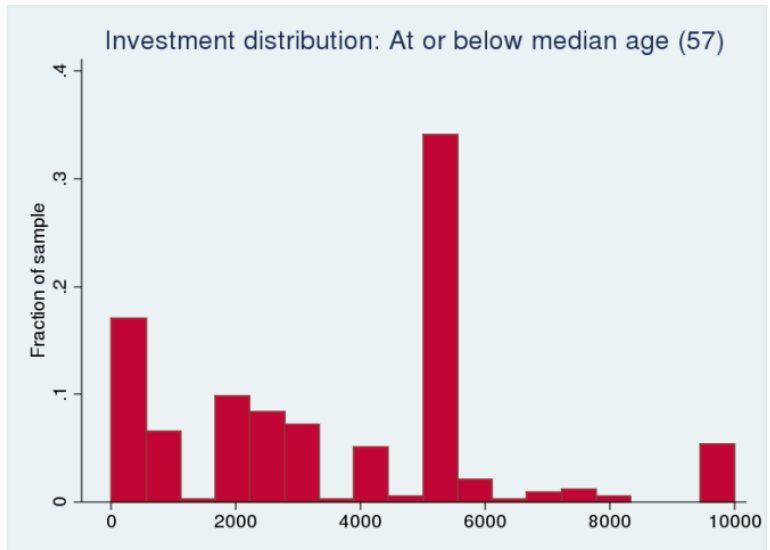

(B)

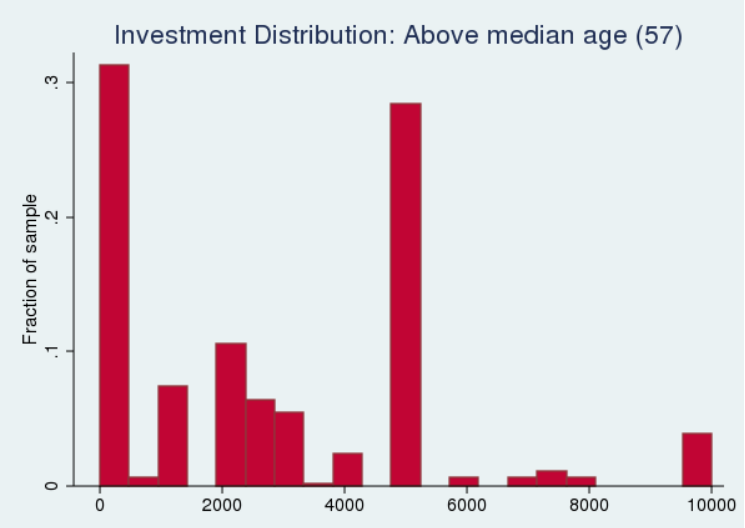

Source: Authors' calculations.

\footnotetext{
${ }^{8}$ Note that in all specifications, adding age squared to capture a nonlinear relationship between age and attitudes towards buying a home does not change any of the results.
} 
Interestingly, looking at the San Francisco housing market, Collins and Choi (2010) find that ZIP-code level changes in home prices during the Great Recession did not influence attitudes on buying a home. They measured home buying attitudes by querying individuals on how likely they were to buy a home in the next six, 12, and 36 months; whether the benefit of owning exceeded the risks; how likely they were to recommend that a friend buy a home in their neighborhood; and their beliefs regarding the potential to profit from selling a home in the future. While these questions clearly differ from our rent-versus-own question, they are very close in spirit. Although Collins and Choi did not find that a change in home prices affected attitudes towards buying a house, they did find that foreclosure rates influenced some aspects of home buying attitudes - namely, the probability that an individual will recommend that a friend buy a home in the neighborhood, and whether they think that a person who buys a house now will be able to sell it at a profit in the future. For this reason, we ran the same specification as in table 1, column (5) with the mean annual foreclosure rates at the respondents' current location. However, we do not find that foreclosure rates have any effect on home buying attitudes or any effect on the relationship between the other variables and home buying attitudes. ${ }^{9}$

\subsection{Different Age Groups}

As mentioned earlier, the literature indicates that economic experiences may affect the attitudes of different age groups differently. That is, individuals form their beliefs early in life, and hence their experiences at that time are potentially more influential. Applying this logic to the context of our study, it is possible that the real estate market crash affected attitudes of the younger respondents but not those of the older ones. We therefore checked for a break in the data by age. That is, we wanted to see whether holding all else equal, different age groups have systematic differences in attitudes towards buying or renting a home. To check this, we ran the following regression:

\footnotetext{
${ }^{9}$ We also used annual foreclosure rates for the 2008 ZIP-code location, and annual rates in 2008, 2009, 2010 , or 2011. None of these different specifications appreciably changed the results.
} 
This is the same specification as table 1, column (5), with the addition of interactions for each of the explanatory variables, with a dummy variable taking a value of 1 if an individual is older than a given age. We ran this regression for every age in our sample-18 to 95 years old ${ }^{10}$ - and looked for the age break that yields the regression with the highest explanatory power (reflected by the highest pseudo $\left.\mathrm{R}^{2}\right) .{ }^{11}$ We also examined whether in that "best" regression the coefficient on the dummy variable for age group interacted with the drop in HPI, as well as whether the triple interaction of the age dummy variable, the drop in the HPI, and personal experience with the crisis are significant. We find the highest pseudo $R^{2}$ at 58 years of age (just above our median), and examining this regression we find that the main variables of interest are significant (pseudo $\mathrm{R}^{2}=0.1365$, higher than previous highest $\mathrm{R}^{2}$ of 0.085 ; see table 1 ).

Given this breakpoint in the data, we ran an additional regression for each subgroupthat is, the sample of those 58 years old or younger and the sample of those over 58 years old. The results are given in Table 2. We find that the gender and marital status effects found in the regression with the overall sample are mainly driven by the older respondents, while the language effect is driven solely by the younger respondents $\left(\beta_{\text {spanish }}=-1.52, \mathrm{p}<0.01\right)$. (In fact, none of the older respondents used the Spanish version of the survey). More importantly, by splitting the sample we do find a significant relationship between the percentage drop in HPI and confidence in homeownership. Interestingly, this relationship runs in opposite directions for the younger and older groups (58 and under: $\beta_{\mathrm{HPI}}=1.44, \mathrm{p}<0.10$; Over 58: $\beta_{\mathrm{HPI}}=1.66, \mathrm{p}<0.10$ ). This difference in the direction of the relationship across age groups explains the null result evident in the regressions for the entire sample.

For the individuals 58 years old or under, we find different relationships between the 2008 decline in the HPI and confidence in homeownership for those respondents who had first- or second-hand experience of the crisis versus those who were only informationally exposed to the

\footnotetext{
${ }^{10}$ For a subset of the age levels the regression failed to converge, namely, ages 21 to 37 years and 80 to 82 years.

11 This method follows the idea of Ferreira and Gyourko (2011), based on Hansen (2000).
} 
crisis.. Adults aged 58 years or under who had experience with the real estate crash are marginally less confident in the benefits of owning a home versus renting (this effect is the main effect of HPI: $\beta$ HPI $=-1.44, \mathrm{p}<0.10$ ) (recall that "1" means "owning is without a doubt better financially"). However, the confidence in homeownership among those with information only did not change; that is, their confidence in buying a home was unaffected by their geographical location, and thus the magnitude of the crash to which they were exposed had no effect on their outlook. (The interaction of those who had information only with the percentage change in HPI has the opposite sign and same magnitude as the main effect of the percentage change in HPI; Chi-square test, $\mathrm{p}=0.4018$ ).

For individuals over 58 years of age, the effect is the opposite: those who had personal experience with the crash are more likely to express higher confidence in buying a home. This effect is marginally significant at the 10 percent level $\left(\beta_{\text {experience }}=1.66, p<0.10\right)$. For those who only had information, again there is no effect. A chi-square test confirms that the sum of the coefficients - the main effect of percentage drop in HPI, and the interaction of the two-is not different from zero $(\mathrm{p}=0.91) .{ }^{12}$

Hence, the results of these regressions reveal a relationship between the drop in the HPI and confidence in the financial desirability of owning a home. It also reveals that personal experience-being close to someone who was adversely affected by the real estate crash or suffering from it firsthand-plays an important role in this relationship. Having information only but no direct exposure to the crisis - for example hearing about the crisis in the newsdoes not seem to be enough to change attitudes. It is possible that personal experience increases the salience of the crisis or the permanence of any subsequent learning, and that this is the reason that people with experience were significantly affected by the crisis while those who only experienced the crisis through informational media accounts or the experiences of people they were not close to did not change their attitudes toward homeownership.

The results indicate that younger (older) individuals in areas that experienced a large drop in the HPI, and who had personal experience with the real estate crisis, are less (more) confident in

\footnotetext{
${ }^{12}$ Note that adding average annual foreclosure rates in 2011 does not change the results for either one of the age groups.
} 
the financial desirability of buying a home. One question is whether this relationship indicates a real causal change: is it the case that personally experiencing a large drop in housing prices lowers confidence in buying a home, or is it the case that people who congregated in locations that ended up experiencing different drops in housing prices were different to begin with? Likewise, the null effect we find on individuals with information only could be a result of different populations having had different initial attitudes toward homeownership, which then converged after the crash, and therefore it is possible that the housing price drop actually did have an effect on them.

To argue that the coefficient on the term denoting the decline in housing prices in our regression captures a change in confidence, we must be able to say that people in different locations, with varying drops in the HPI, are not different in other relevant dimensions. We cannot argue this with certainty; however, by examining data on observable and relatively fixed variables such as income, age, education, marital status, number of children below 18 years of age, actual homeownership, and risk aversion (as captured by the amount respondents say they would invest in a hypothetical project), we can begin to answer this question. We find no significant correlations ( $>0.3$ in all cases) between these observables and the drop in the HPI. ${ }^{13}$ Moreover, any such population differences would have to explain the opposite signs on younger and older individuals, and it is not clear how a priori selection could have led to this particular dichotomy in confidence.

There is another, yet similar, reason to believe that people in different geographic locations did not have different initial attitudes towards home buying: in all our regressions, the main effect of having only information is insignificant. That is, the two communities - those people who had personal experience with the crisis and those who had information only-do not appear to differ except in the different relationships between the HPI drop and confidence in home buying. Since two-thirds of our sample had exposure to the crisis through information only and the range of different drops in the HPI did not vary across those with and without personal experience (see Figure 7), the possibility that a drop in the HPI is correlated with different initial attitudes towards buying a home appears considerably less likely.

\footnotetext{
${ }^{13}$ The only demographic variable for which we do find any correlation is race.
} 
Of course, even accepting that geographic variation based on the HPI drop is not correlated with different initial attitudes towards homeownership, it is possible that the crisis in the real estate market did not affect attitudes towards owning a home per se, but rather affected risk attitudes. However, we ran another regression that controlled for risk attitudes by including the amount one would like to invest in a risky project as an explanatory variable and found a similar effect of change in the HPI. To investigate this concern further, we regressed the response to the investment decision on the same specification as the rent-versus-own question. Here, we were looking to see whether the percentage change in the HPI has any effect on risk aversion, as captured by the response to the investment question. The results are presented in table A4 in the appendix. We find that whether examining the entire sample or each of the two age groups separately, the percentage change in the HPI does not affect the hypothetical investment decision. Furthermore, we find that the null effect of a change in the HPI on investment is similar whether or not the individual directly experienced the housing crisis. The absence of a house price effect on the willingness to invest, our proxy for risk aversion, is inconsistent with the idea that the HPI's effect on confidence in buying a home is due to the HPI's effect on risk aversion.

Going back to the results in table 2, we can summarize the results by saying that information only does not affect attitudes, while experience does. Yet the immediate question is why experience with the crash increased the likelihood of confidence in the financial advantage of buying a home for the older age group.

Higher homeownership rates among the older individuals cannot be the explanation per se, since the difference in confidence is based on personal experience (first- or second-hand) with the crisis rather than with homeownership itself. It is possible, however, that those who have had personal experience with the real estate market crash have different homeownership composition characteristics across the different age groups. If, for instance, those in the older group who have had direct experience are the same individuals who own a home rather than rent, while the opposite holds true for the younger group, this dichotomy might explain the different results across age groups. Examining the correlation of personal experience and homeownership, we find small and insignificant negative correlations for both age groups: 
-0.07 for the younger group $(p=0.11)$, and -0.04 for the older group $(p=0.39)$. A negative correlation implies that homeownership (1=owning, $2=$ renting) and personal experience (1=experience, 2 =information only) run in opposite directions. That is, those who directly experienced the real estate market crash are more likely to be renters. Yet we find no significant correlation, and we find that among the older age group, having personal experience with the crisis, which is correlated with being a renter, is related to having more confidence in the financial benefits of owning a home.

Examining the older individuals, we find that in this subgroup the median respondent is 68 years old. This fact, along with the question's broad phrasing (in particular, the lack of distinction between whether their experience of the crash was first- or second-hand), may be the reason for this result. More specifically, a 68-year-old who owns a home is more likely than a younger individual to have bought his or her house a few decades ago and to have made a net profit from this investment in spite of the recent drop in house prices. If this is the case for many of the older subjects, then the greater the actual drop in the housing market that their investment has withstood, the more confident the individual may become in the desirability of buying rather than renting a home. Furthermore, since the older group has many people over 68 years of age, implying longer tenures in their place of residence, it is less likely that owners in this group were foreclosed on even if they lost a substantial amount of money in the housing crash, as compared with the younger group.

We argued that personal experience may be instrumental in whether the housing crash impacts upon one's confidence in homeownership. However, it is possible that personal experience is itself a result of a large drop in the HPI and that in effect we have a threshold-type model: below a certain threshold (for the fall in housing prices) individuals simply do not pay attention to the crisis and hence their confidence in buying a home is intact, while above the threshold people do pay attention and as a result their confidence is affected. This would yield our result purely mechanically, rather than because there was actually a direct link between experience and attitudes.

To examine this argument, we plot the histogram of the percentage change in the HPI from peak to trough at the 2008 location by whether individuals had personal experience ("Had 
experience") or did not ("Had information only") with the 2008 real estate crisis (see figure 7). Eyeballing the graphs, we do find that among individuals who have experienced the market downturn, a large drop in the HPI is more prevalent. A Mann-Whitney test confirms the difference in distributions $(\mathrm{p}=0.00)$ and a probit regression that explains the probability of having personal experience with the crisis, controlling for homeownership and age, shows that the HPI drop in 2008 has a significant positive effect on the probability of having personal experience with the crisis. Nevertheless, we can also see from figure 7 that there is a considerable fraction of individuals who have had direct experience with the crisis and yet experienced a relatively low drop in the HPI in their 2008 residential location; likewise, there is a significant fraction of individuals who were exposed to the crisis through information only even though the HPI dropped considerably in their residential location in 2008. This is reflected in the average drop in the HPI in the 2008 location: a 31.1 percent drop among those who had personal experience, and a 25.5 percent drop among those who had information only. Hence, although those respondents who lived in an area that had a large drop in the HPI are more likely to have had personal experience with the crisis, the results do not appear to reflect a threshold-type model, where one pays attention to the crisis only if the drop in HPI is above a certain level.

Figure 7: Distribution of drop in HPI

For those with experience and those with information only

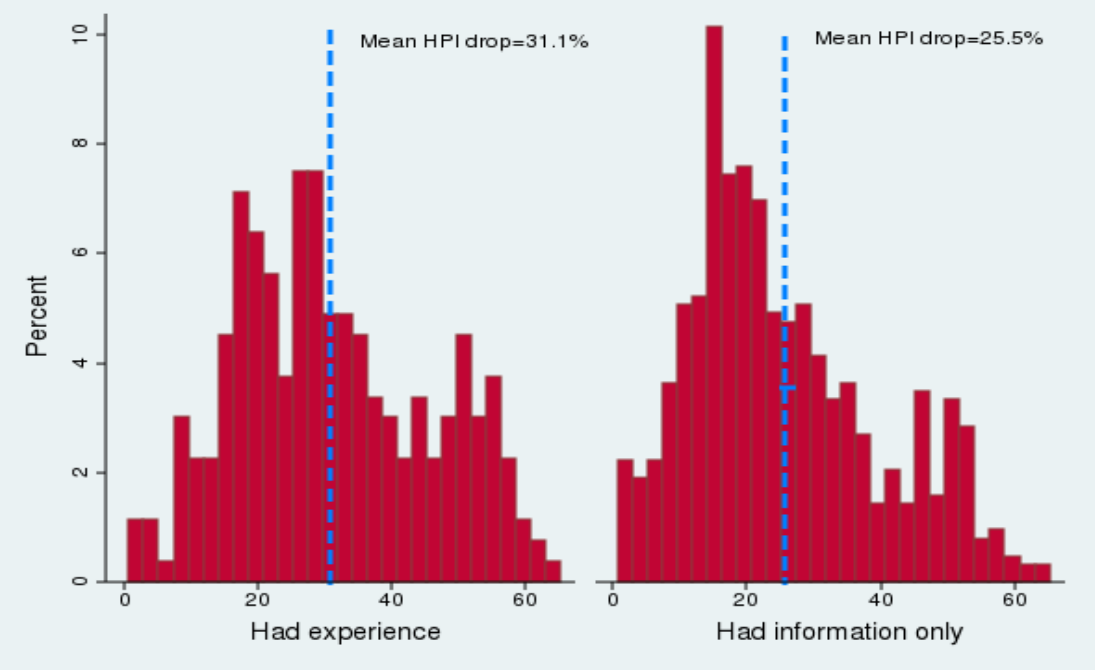

Source: Authors' calculations. 
In the analysis above we examined the relationship between a drop in the HPI and confidence in the desirability of home buying compared with renting. We did this by distinguishing strong confidence in buying from all other possible responses to our "rent versus own" question. One may wonder whether our results are driven by attitudes changing from favoring buying towards a preference for renting, or by an actual difference in confidence about buying a home. To examine this, we opted for two additional classification schemes: the first classifies the two confidence-in-buying categories together as " 1, " and the two confidence-inrenting categories as "0." We excluded those respondents who expressed indifference between buying and renting a home. We then ran the same specification as in table 2, column (5), and found that the decline in the HPI had no significant effect on attitudes among the young or the old, probably as a result of the relatively small sample size of those who prefer renting. Next, we examined confidence in home buying, restricting our attention to only those who expressed a favorable view of homeownership. We classified strong confidence in homeownership as "1" and lower confidence in homeownership as "0." In this case, we found no significant effect of the HPI drop on confidence among the older age group, but we found the same previous effect on the younger group. As before, we found no similar effect on those individuals who had exposure to the crisis through information only $(p=0.25)$. These additional regressions are presented in tables A2-3 in the appendix.

Finally, recall that our entire analysis uses a binary probit model of confidence. This is necessary for the alternative specifications discussed in the previous paragraph, but the original variable (with five outcome categories) could suggest employing an ordered probit approach instead. The main reason we avoided using that alternative was because the data suggested a binary split, with only two categories accounting for the vast majority of responses. However, as a robustness check we ran the ordered probit and found that the main HPI effect (moving from the first to the second response category) is in the same direction for both age groups as in our results above, and highly significant for the older respondents.

To summarize our results for preferring homeownership, experience emerges as an important factor affecting an individual's confidence toward buying a home. For the older age group, experiencing the crisis is associated with stronger home-buying confidence, while for 
the younger age group, experiencing the crisis is instead associated with shaken confidence in the desirability of buying a home. To get a sense for the magnitude of these effects, we calculated (separately for the older and younger age groups) what would be the predicted probability of a strict preference for ownership at each possible value of the HPI drop, following exposure to the crisis through either experience or information only. The results, shown below in figure 8, are quite striking and show that this effect has economic as well as statistical significance.

Figure 8: HPI drop and predicted probability of preference for owning

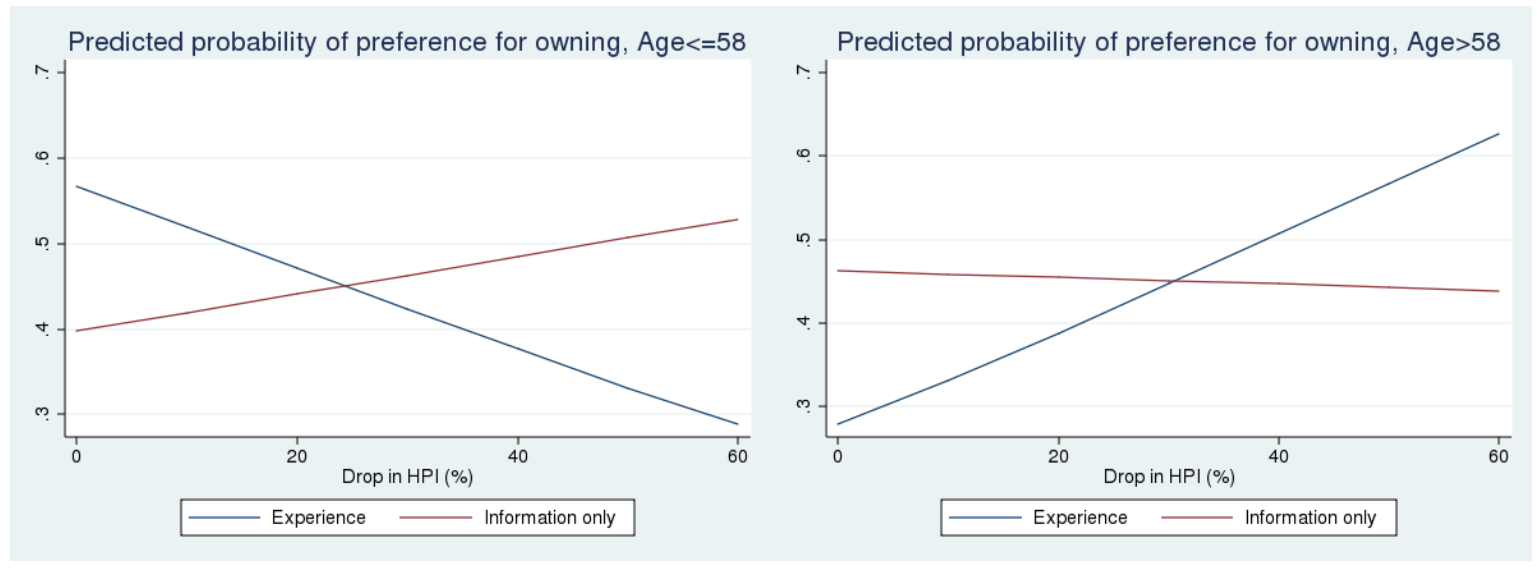

Source: Authors' calculations.

The HPI's differential effect on younger and older individuals who have personally experienced the housing crisis is intriguing. Yet one may wonder whether this effect is consistently negative for all age groups below 58 years old and positive for all age groups older than 58 years. As a first pass at answering this question, we ran the same specification as in table 2 (column 5) for individuals below the age of 45 years, only for those between the ages of 45 and 58 years, only for those between the ages of 58 and 67 years, and finally for individuals older than 67 years. In figure 9 we report, for each of the four age groups, the point estimate of the coefficient on HPI drop for individuals with direct personal experience. We find that the drop in the HPI has a negative effect on both age groups younger than 58 years and a positive effect of both age groups above 58 years, consistent with our prior conclusions. Interestingly, 
the crisis's strongest negative effect on attitudes towards homeownership is found among the youngest individuals: below 45 years old. This result is in line with past literature that finds decreasing impressionability as people get older.

Figure 9: Effect of HPI by Age Group for those with Experience

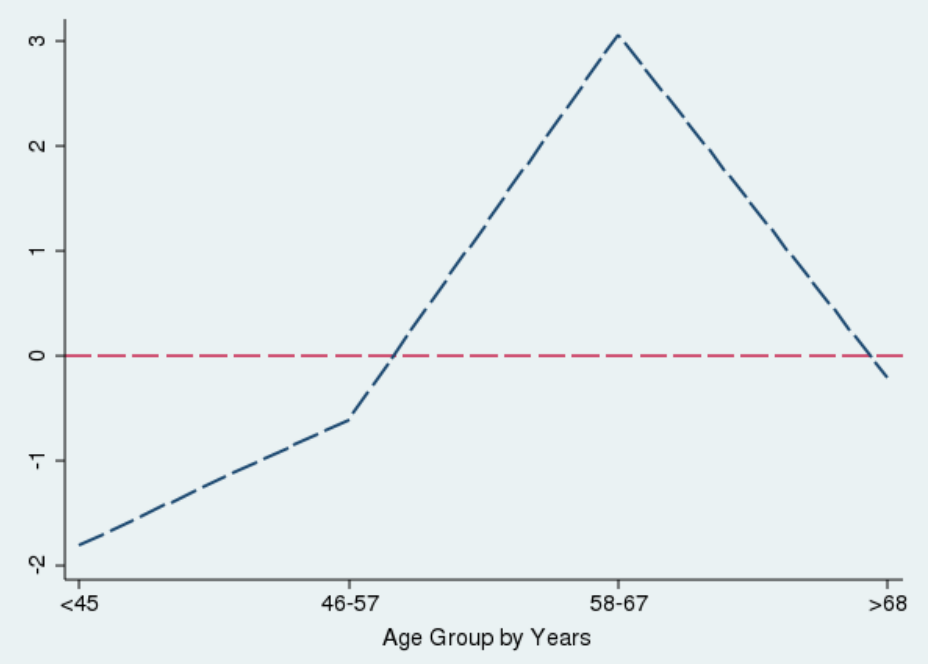

Source: Authors' Calculations.

Lastly, we report the regression analysis using a dummy for current homeownership and a proxy for risk aversion as explanatory variables. As Stefan Nagel points out in his comments, these variables are measured after the 2008 crash and may therefore capture part of the effect of the crisis on homeownership attitudes. To investigate this possibility, we ran the same regression specification as before, but dropping these explanatory variables both singly and together. We found very similar results for both age groups: the main HPI effect on homeownership attitudes varies for the younger group between -1.45 and -1.50 , and for the older group between 1.64 and 1.75. As expected, the effect becomes somewhat stronger after taking away the current homeownership dummy, but this change is minor. 


\subsection{Mortgage Spending}

The second question of interest is whether the different experiences individuals had with the real estate market crash changed what they consider to be a reasonable monthly mortgage expense. In other words, since the crash have people become more conservative in their real estate spending, a response that could shed light on the future demand for housing. To investigate whether individuals became more conservative about home buying as a result of their crisis experience, we asked the following question:

Suppose that a family of an average size has an income of $\$ 4,000$ a month after taxes and that the family would like to buy a house. In your opinion, what is the maximum monthly payment that this family should make on its mortgage?

We then used an ordinary least squares regression to explain the amount that individual respondents indicated is reasonable for this hypothetical family to spend on a monthly mortgage payment. We used a similar specification to explain changes in buying confidence, examining the effect of demographics, including age, gender, marital status, education, income, number of children under 18 years old, race, homeownership, and language, as well as the effect of neighborhood characteristics, such as racial composition, gender composition, poverty level, and percentage of college graduates in the area. We then added the percentage change in the HPI (our main variable of interest), a dummy variable to capture whether the respondent had exposure to the crisis through information only, the interaction of this dummy variable with the change in the HPI, and the HPI level and standard deviation in 2011 for the so-called peak-end rule. We further added the percentage change in gas prices, since the price of gasoline (like any other nontrivial expenditure) influences the household budget and should therefore affect the choice of how much to spend on the mortgage. We also added the response for investment to control for risk aversion, with the idea that the more risk-averse a person is, the less she may be willing to spend on a mortgage. We then added an interaction of the investment decision with age, as risk aversion is thought to increase with age. 
The results are shown in table 3. Although we cannot compare these responses to the responses that individuals would have given before the crisis, we can explore the relationship between the housing crisis and attitudes towards mortgage payments by comparing people in different locations with different experiences. We find a positive and significant coefficient for the drop in the HPI on mortgage spending. This is true for the sample overall ( $\beta_{\text {HPIdrop }}=601$, $\mathrm{p}<0.01)$ and for those respondents 58 years old or younger $(\beta=1168$ HPIdrop, $p<0.01)$. For respondents over 58 years of age, the main effect of the HPI is negative and insignificant ( $\beta_{\mathrm{HPI}=-}$ 214). A positive number implies that the greater the drop in the HPI, the more one thinks a family should spend on a monthly mortgage payment. This main effect of the HPI drop on mortgage spending is for those individuals who had exposure to the real estate crisis through experience (either first- or second-hand). The effect of the HPI drop on those only informationally exposed to the housing crisis is lower, but still positive overall.

The prima facie implication of this result is that the greater the drop in the HPI, the higher the amount individuals think that the hypothetical family should spend on a mortgage. This seems counterintuitive, but it could be a result of strategic thinking: if one thinks that it is a good time to buy real estate, it may be worth investing more in real estate (and hence paying a higher percentage of income). Alternatively, these responses may reflect awareness of the tighter lending practices in place since the housing bust-people may realize that as a result of the crash banks will be stricter in their lending criteria. For example, banks may not offer variable-rate mortgages, low teaser rates, or other incentives to borrow, all of which were increasingly common when it was assumed that housing prices would only continue to rise. Hence, even for the same or lower house price, the monthly mortgage payment may need to be higher.

However, in this case it is also possible that the link at least partially runs in the other direction. If for some reason individuals who believe in spending more on housing aggregate together, or if people in certain geographic areas gravitate toward such beliefs as a group, then these communities and regions might end up facing more extreme housing bubbles and crashes-leading to the observed results in the data. Either way, and interestingly, for mortgage spending the end effect is driven by the HPI level at the end of the period; that is, the higher the 
HPI level in the respondent's 2011 location, the more he or she thinks a family should spend on a mortgage. This makes sense: in areas where the average house price is higher, people need to spend more on mortgages.

\subsection{Commuting versus Housing Prices}

A third question of interest is whether the different experiences individuals had with the real estate market crash changed their willingness to accept longer commutes as a means to achieving lower housing expenses. If such an effect exists, it may shed light on future attitudes toward the housing market. Specifically, if markets that experienced a large drop in the HPI have a substantial share of residents who are willing to relocate in order to reduce housing expenses, then these markets may have trouble recovering from the drop in prices. Finding such a pattern may also indicate whether we should expect housing prices to increase more in the distant suburbs than in areas closer to city centers.

To investigate how an individual's experience of the housing market downturn affected her willingness to commute, we asked the following question:

We are interested in your attitude towards commuting to work-specifically, how willing are you to increase your commute to work if that would reduce your housing expenses? Which of the following five options best describes your opinion: 1) you are not at all willing to increase your commute if it would reduce your housing expenses; 2) you are somewhat unwilling; 3) you are neither willing nor unwilling; 4) you are somewhat willing; or 5) you are definitely willing to increase your commute if it would reduce your housing expenses?

The average response in the sample to the "commute" question was 3.22, indicating that, on average, respondents were neither willing nor unwilling to substitute more commuting time for lower housing expenses. A histogram of the distribution of the responses is presented in figure 10. Note that for this analysis we exclude individuals who reported that they were retired or did not have a job, since commuting to work is not relevant for them. 
Figure 10: Willingness to Commute

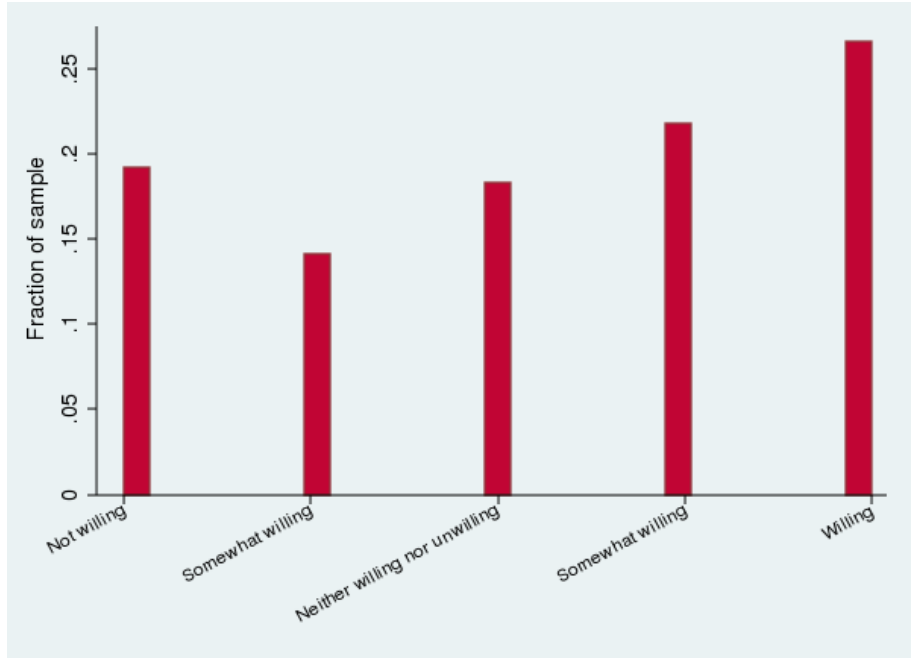

Source: Authors' calculations.

As figure 10 reveals, responses to the commuting question are quite evenly distributed, with some skewtoward "willingness" to commute in order to defray housing expenses.

In the sample, willingness to commute is coded as an ordinal variable, with values of $1-5$, where 1 is not at all willing to commute and 5 is definitely willing to commute. Since about half the sample (51.68 percent) answered 1-3, capturing different degrees of unwillingness to commute, and the other half answered 4-5 capturing different degrees of willingness to increase commute, we chose to recode the commute variable as a binary variable in order to capture the crude difference between positive or negative attitudes towards commuting. We therefore coded the values 1,2 , and 3 as " 0 " and the values 4 and 5 as " 1 ," where " 1 " captures a willingness to undertake a longer commute.

We then ran a probit regression to explain a given respondent's willingness to commute. Using a similar specification to the one for the rent-versus-own question, we examined the effect of demographics (such as age, gender, marital status, education, income, number of children younger than 18 years, race, homeownership, and language) as well as the effect of neighborhood characteristics, such as racial composition, gender composition, poverty level, and percentage of college graduates in the area, on the respondent's willingness to commute. We also included a dummy variable capturing exposure to the crisis via information only, the 
percentage change in the HPI in the 2008 location, the interaction of the HPI drop with the dummy variable for information only, as well as the HPI level and standard variation in 2011, to capture the "peak-end" effect. We also included the current level and standard deviation of gas prices in the 2011 location, since gas prices are likely to affect commuting decisions. We first ran regressions using both housing and gas price variables, and then only with gas price variables.

We also added the response to the hypothetical investment decision to control for risk aversion, in case there is a relationship between risk tolerance (financial or otherwise) and the willingness to commute. We then added an interaction of the investment decision with age, as before. We ran the same specification for the overall sample and then for the sample by age. The results are presented in table 4.

As table 4 shows, we do not find that the housing market decline had any significant effect on the respondents' willingness to commute. The direction of the coefficients is negative, signifying that for a larger drop in the housing market, individuals would be less likely to be willing to commute. This result is justifiable by the fact that individuals are asked whether they would be willing to commute in order to offset housing expenses, which presumably would not be as high given a larger decline in their area's market. However, the effect is statistically insignificant. In addition, this response does not seem to be affected by whether one was exposed to the crisis through experience or through information only; nor by the interaction between information only and the decline in housing prices. Overall, there appears to be little evidence to suggest that directly experiencing the housing downturn had any effect on the respondent's willingness to commute. This insignificance result also persists when we split the sample into our two primary age groups, indicating that there is no difference by age in the effect that experiencing the housing downturn has on attitudes towards commuting.

Interestingly, none of the specifications offer evidence that current gas price levels have a significant effect on commuting attitudes. Somewhat counterintuitively, the sign of the coefficient is always positive; however this effect is always insignificant. The volatility coefficient is negative, indicating that more uncertainty about gas prices implies less willingness to commute, although this effect is also insignificant in most specifications. 
It is possible that we do not find that gas prices have an effect on one's willingness to commute because, given the volatility of gas prices in recent years, past experience is not highly predictive of future expectations. Therefore, it would be interesting to see whether expectations regarding gas prices have an effect on commuting attitudes. In fact, such a question does exist in the Michigan survey questions, to which we had access; however, due to the infrequency of the responses, including it in our regressions would have cut our sample in half (resulting in an overall sample of 404 individuals across ages). Nevertheless, when we included expectations about gas prices as an explanatory variable, we did find that gas-price expectations matter for one's willingness to commute: if an individual expects gas prices to decrease, he or she is more likely to be willing to commute than is an individual who expects gas prices to increase. This result is robust to splitting the sample by age.

Overall, it seems that direct experience with the housing market decline in 2008 and experience of changes in gas prices have had no effect on attitudes towards commuting. While there may have been an effect through gas-price expectations, we do not find evidence for it. ${ }^{14}$

\section{Conclusions}

This paper addresses the question of whether the recent U.S. housing crash affected individuals' confidence in homeownership, which is historically a central life goal for many people. In order to do this, we surveyed 986 individuals during July and August 2011, asking them about their attitudes toward buying versus renting a home, paying a mortgage, and commuting. We matched their responses to the specific house price decline in their ZIP code, and examined whether the actual HPI decline in their locality affected their confidence in homeownership. Our identification strategy rests on the fact that we find no differences in observable individual characteristics (such as homeownership, income, or even risk aversion) across different ZIP codes that experienced various levels of decline in real estate prices. Our results are supported

\footnotetext{
${ }^{14}$ We ran a regression of gas-price expectations on the percentage change in gas prices and housing prices, as well as on 2011 averages and standard deviations of house and gas prices. We did not find that any of these variables had a significant effect on expectations. This lack of significance was true both for the overall sample and for each age group separately.
} 
by finding different effects for different age groups, which is more difficult to explain via preexisting variation.

We find that recent housing market conditions had little effect on individuals whose exposure to the crisis came through information only, such as media accounts. For individuals who were not foreclosed on, did not lose a substantial amount of money in real estate, and did not have anyone close to them who did, attitudes towards the financial soundness of buying as opposed to renting were unchanged by the magnitude of the house price decline in their area. This result is also evident in the lack of effect that the decline in home prices has on the willingness to increase one's commute in order to reduce housing expenses. However, we do find a positive link between the drop in housing prices and the maximum amount individuals think a family ought to spend on a mortgage. Those who did have personal experience with the crisis appear to have been influenced by the housing-price decline, but this effect varies by age. The greater the drop in home prices that occurred in their location, the less confident those individuals who are relatively young (under 58 years of age) are in the soundness of buying a home. At the same time, those individuals over 58 years of age who did have personal experience with the crisis have more confidence in the soundness of buying a home, and this result is stronger the greater the drop in home prices in their location.

This study provides two main insights: first, direct personal experience with a financial shock plays a central role in determining whether individual attitudes change. Even an extremely negative experience such as the Great Recession, the worst U.S. economic crisis since the Great Depression, was not enough to shift the attitudes of those who lived through the crisis - and thus had full access to information on its effects - but did not have strong first- or second-hand experience of these adverse effects. As the Great Recession was a severe and extreme situation, this analysis may point to a more general rule: information alone may not be sufficient to change attitudes; rather actual experience is necessary to change attitudes. Furthermore, the crisis's effects seem to be confined to attitudes toward buying a home, and do not extend to attitudes related to other homeownership decisions, such as commuting or general risk aversion. 
The second insight, consistent with some past studies (for example, Giuliano and Spilimbergo 2009), is our finding that real estate prices mainly had a negative effect on younger individuals' confidence in buying a home, whereas, interestingly, the drop in house prices is associated with older individuals' gaining more confidence in the financial soundness of buying rather than renting a home. This observation is consistent with the idea that older individuals have a fixed set of beliefs and interpret the crisis as a temporary decline from a known trend. In contrast, the younger individuals who personally experienced the recent drop in house prices tended to have lower confidence in buying a home, a finding consistent with the idea that their beliefs are still flexible and can change over time. 


\section{References}

Bellows, John, and Edward Miguel. 2006. "War and Institutions: New Evidence from Sierra Leone." American Economic Review 96(2): 394-399.

Clark, Andrew E., and Yannis Georgellis. 2004. "Kahneman Meets the Quitters: Peak-End Behaviour in the Labour Market." Working Paper. Paris: Paris School of Economics.

Available at http://www.parisschoolofeconomics.com/clark-andrew/kqv3.pdf.

Collins, J. Michael, and Laura Choi. 2010. "The Effects of the Real Estate Bust on Renter Perceptions of Homeownership." Community Development Working Paper 2010-01. San Francisco: Federal Reserve Bank of San Francisco. Available at http://www.frbsf.org/publications/community/wpapers/2010/wp2010-01.pdf.

Eckel, Catherine C., Angela De Oliveira, and Philip J. Grossman. 2007. "Is More Information Always Better? An Experimental Study of Charitable Giving and Hurricane Katrina." Southern Economic Journal 74(2): 388-411.

Engelhardt, Gary V. 2011. “The Great Recession and Attitudes toward Home-Buying.” Research Institute for Housing America Special Report. Washington, DC: Mortgage Bankers Association. Available at

http://www.housingamerica.org/RIHA/RIHA/Publications/79074_11034_Research_RIHA_Reput ation_Report.pdf.

Ferreira, Fernando, and Joseph Gyourko. 2011. "Anatomy of the Beginning of the Housing Boom: U.S. Neighborhoods and Metropolitan Areas, 1993-2009.” Working Paper No. 17374. Cambridge, MA: National Bureau of Economic Research.

Giuliano, Paola, and Antonio Spilimbergo. 2009. "Growing up in a Recession: Beliefs and the Macroeconomy." Working Paper No. 15321. Cambridge, MA: National Bureau of Economic Research.

Guiso, Luigi, Paola Sapienza, and Luigi Zingales. 2011. "The Determinants of Attitudes towards Strategic Defaults on Mortgages.” Working Paper. Evanston, IL: Northwestern University.

Available at

http://www.kellogg.northwestern.edu/faculty/sapienza/htm/Guiso Sapienza Zingales Strategi cDefault.pdf.

Hansen, Bruce. 2000. “Sample Splitting and Threshold Estimation." Econometrica 68(3): 575-603.

Kahneman, Daniel. 1999. “Objective Happiness.” In Well-Being: The Foundations of Hedonic Psychology, ed. Daniel Kahneman, Ed Diener, and Norbert Schwarz, 3-25. New York: Russell Sage. 
Lerner, Jennifer S., and Dachar Keltner. 2001. "Fear, Anger, and Risk." Journal of Personality and Social Psychology 81(1): 146-159.

Malmendier, Ulrike, and Stefan Nagel. 2009. “Learning from Inflation Experiences.” Working Paper. Berkeley: University of California. Available at

http://www.econ.berkeley.edu/ ulrike/Papers/InflExp_4.pdf.

Malmendier, Ulrike, and Stefan Nagel. 2011. "Depression Babies: Do Macroeconomic Experiences Affect Risk Taking?" Quarterly Journal of Economics 126(1): 373-416.

Molloy, Raven, and Hui Shan. 2011. “The Post-Foreclosure Experience of U.S. Households in the Current Housing Market Downturn." Finance and Economics Discussion Paper, 2011-32. Washington, DC: Board of Governors of the Federal Reserve System.

Available at http://www.federalreserve.gov/pubs/feds/2011/201132/201132pap.pdf.

Morin, Roger A., and Antonio Fernandez Suarez. 1983. "Risk Aversion Revisited." Journal of Finance 38(4):1201-1216.

Mudd, Shannon, Konstantin Pashev, and Neven Valev. 2010. "The Effect of Loss Expectations in a Banking Crisis on Future Expectations and Behavior." The B.E. Journal of Macroeconomics 10(1): $1-19$.

Nishiyama, Yasuo. 2006. “The Asian Financial Crisis and Investors' Risk Aversion." Asia-Pacific Financial Markets 13(3): 181-205.

Nunn, Nathan, and Leonard Wantchekon. 2009. "The Slave Trade and the Origins of Mistrust in Africa." Working Paper No.14783. Cambridge, MA: National Bureau of Economic Research.

Osili, Una and Anna Paulson. 2009. "Banking Crises and Investor Confidence: An Empirical Investigation." Policy Discussion Paper 2009-9. Chicago: Federal Reserve Bank of Chicago. Available at http://www.chicagofed.org/webpages/publications/policy_discussion_papers/2009/pdp_9.cfm.

Panchuk, Kerri. 2011. “Fannie Mae: Negative Equity Environment Saps Would-be Homebuyers." Available at http://www.housingwire.com/2011/08/15/fannie-mae-negativeequity-environment-saps-would-be-homebuyers.

Simonsohn, Uri, Niklas Karlsson, George Loewenstein, and Dan Ariely. 2008. "The Tree of Experience in the Forest of Information." Games and Economic Behavior 62(1): 263-286.

Starobin, Paul. 2011. “A Dream Endangered (Yeah, So?)” National Journal, Mar 17. Available at http://www.nationaljournal.com/njonline/no_20100508_1960.php/the-enduring-dream-ofhomeownership-20110317. 
Taylor, Paul, Kim Parker, Rakesh Kochhar, Wendy Wang, Gabriel Velasco, and Daniel Dockterman. 2011. "Home Sweet Home. Still." Social and Demographic Trends, Apr 12. Washington, DC: Pew Research Center. Available at http://www.pewsocialtrends.org/2011/04/12/home-sweet-home-still/.

U.S. Census Bureau. 2011. Current Population Survey/Housing Vacancy Survey, Series H-111 Reports. Washington, DC: Bureau of the Census.

Voors, Maarten, Eleonora Nillesen, Philip Verwimp, Erwin Bulte, Robert Lensink, and Daan van Soest. Forthcoming. "Does Conflict Affect Preferences? Results from Field Experiments in Burundi." American Economic Review.

Weinstein, Neil. 1989. “Effects of Personal Experience on Self-Protective Behavior." Psychological Bulletin 105(1): 31-50. 
Tables

Table 1. Rent-versus-Own Probit Regression

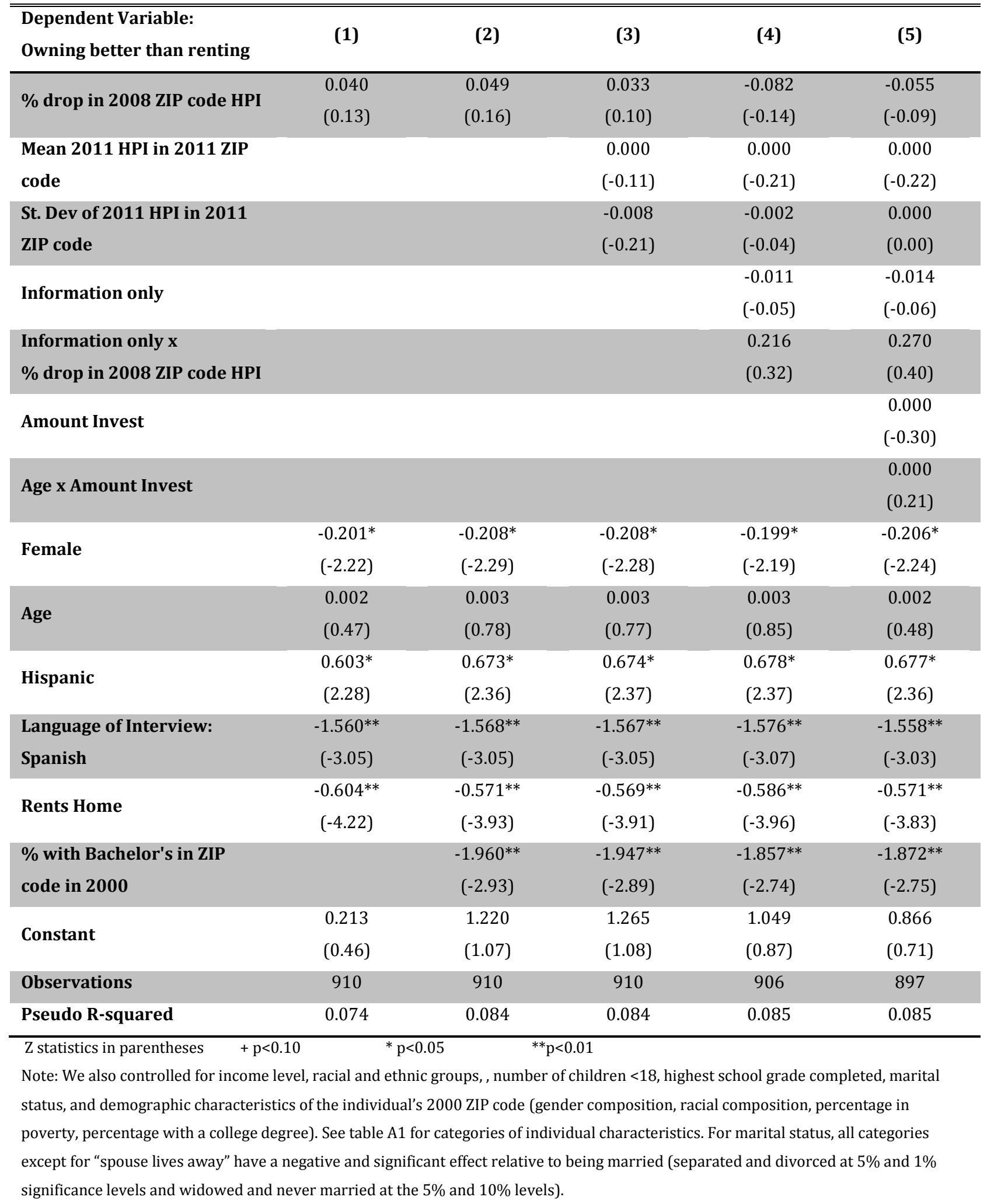


Table 2. Rent-versus-0wn Probit Regression, by Age Group

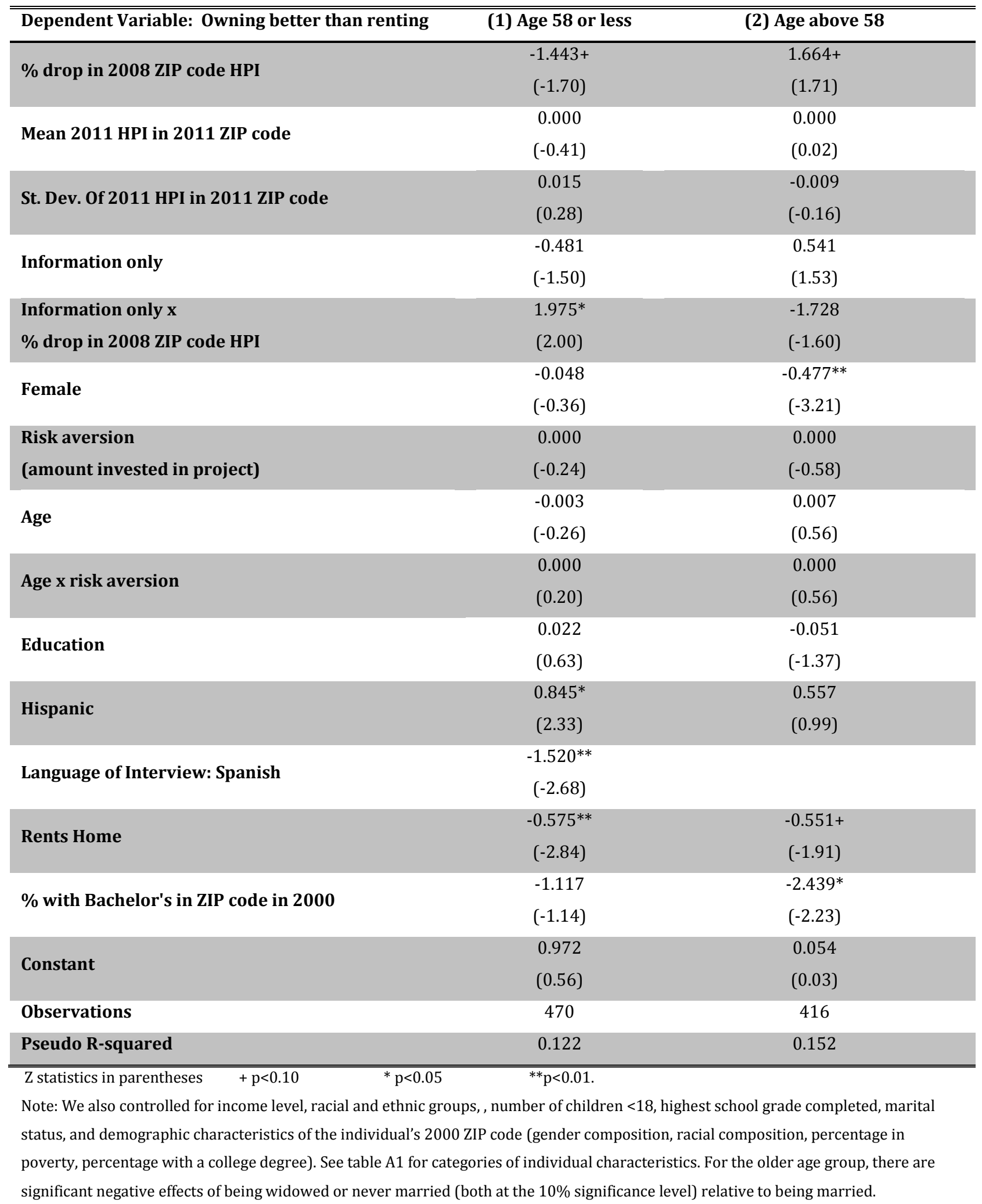


Table 3. Maximal Mortgage Spending

\begin{tabular}{|c|c|c|c|}
\hline Dependent Variable: Max. monthly mortgage payment & (1) All ages & (2) Age $<=58$ & Age $>58$ \\
\hline \multirow[t]{2}{*}{ \% drop in $2008 \mathrm{ZIP}$ code HPI } & $600.7^{* *}$ & $1167.5^{* *}$ & -214.1 \\
\hline & $(2.85)$ & $(4.16)$ & $(-0.60)$ \\
\hline \multirow[t]{2}{*}{ Mean 2011 HPI in 2011 ZIP code } & $2.364^{* *}$ & $2.822^{* *}$ & 1.351 \\
\hline & $(3.25)$ & $(2.92)$ & $(1.15)$ \\
\hline \multirow[t]{2}{*}{ St. Dev of 2011 HPI in 2011 ZIP code } & -20.47 & $-33.79 *$ & 3.822 \\
\hline & $(-1.65)$ & $(-2.03)$ & $(0.19)$ \\
\hline \multirow[t]{2}{*}{ Information only } & 56.64 & $197.6+$ & -84.16 \\
\hline & $(0.77)$ & $(1.91)$ & $(-0.75)$ \\
\hline Information only $x$ & -243.5 & $-684.2^{*}$ & 283.0 \\
\hline \% drop in $2008 \mathrm{ZIP}$ code HPI & $(-1.09)$ & $(-2.17)$ & $(0.80)$ \\
\hline \multirow[t]{2}{*}{ Female } & -13.71 & -51.03 & 16.29 \\
\hline & $(-0.44)$ & $(-1.18)$ & $(0.34)$ \\
\hline \multirow[t]{2}{*}{ Amount Invest } & -0.003 & -0.044 & -0.059 \\
\hline & $(-0.12)$ & $(-1.28)$ & $(-0.75)$ \\
\hline \multirow[t]{2}{*}{2011 mean annual gas price } & 321.4 & 5.321 & $1016.1^{*}$ \\
\hline & $(1.30)$ & $(0.02)$ & $(2.41)$ \\
\hline \multirow[t]{2}{*}{2011 std dev annual gas price } & -657.8 & -553.6 & -375.7 \\
\hline & $(-1.09)$ & $(-0.65)$ & $(-0.40)$ \\
\hline \multirow[t]{2}{*}{2009 mean annual milk price } & 1621.6 & 516.0 & 2883.5 \\
\hline & $(1.01)$ & $(0.23)$ & $(1.21)$ \\
\hline \multirow[t]{2}{*}{2009 std dev annual milk price } & -990.3 & -11477.1 & 12430.9 \\
\hline & $(-0.15)$ & $(-1.23)$ & $(1.26)$ \\
\hline \multirow[t]{2}{*}{ Age } & -1.569 & $-9.365^{* *}$ & $-13.11^{* *}$ \\
\hline & $(-0.25)$ & $(-2.62)$ & $(-2.99)$ \\
\hline \multirow[t]{2}{*}{ Age $^{2}$} & -0.031 & & \\
\hline & $(-0.58)$ & & \\
\hline \multirow[t]{2}{*}{ Age x Amount Invested } & 0.000 & 0.001 & 0.001 \\
\hline & $(0.22)$ & $(1.52)$ & $(0.68)$ \\
\hline \multirow[t]{2}{*}{ Rents Home } & 16.34 & 65.34 & -3.069 \\
\hline & $(0.35)$ & $(1.06)$ & $(-0.04)$ \\
\hline \multirow[t]{2}{*}{ Constant } & -98.84 & 1459.8 & -1687.9 \\
\hline & $(-0.12)$ & $(1.32)$ & $(-1.33)$ \\
\hline Observations & 860 & 460 & 400 \\
\hline R-squared & 0.175 & 0.221 & 0.222 \\
\hline
\end{tabular}

T statistics in parentheses, $+\mathrm{p}<0.10,{ }^{*} \mathrm{p}<0.05,{ }^{* *} \mathrm{p}<0.01$.

Note: We also controlled for income level (see table A1 for categories), racial and ethnic groups (white, Black, Hispanic, Asian, and American Indian or Alaska native), demographic characteristics of the individual's 2000 ZIP code (gender composition, racial 
composition, percentage in poverty, percentage with a college degree), number of children $<18$, highest school grade completed, and marital status (married, never married, separated, divorced, and spouse lives away).

Table 4. Commute

\begin{tabular}{|c|c|c|c|c|c|c|}
\hline Dependent Variable: & (1) & (2) & (3) & (4) & (5) & (6) \\
\hline Willingness to commute & All ages & Age $<=58$ & Age $>58$ & All ages & Age $<=58$ & Age $>58$ \\
\hline$\%$ drop in $2008 \mathrm{ZIP}$ code & -0.713 & -1.017 & -0.944 & & & \\
\hline HPI & $(-1.11)$ & $(-1.13)$ & $(-0.85)$ & & & \\
\hline Mean 2011 HPI in 2011 & 0.000 & -0.003 & 0.003 & & & \\
\hline ZIP code & $(-0.20)$ & $(-1.06)$ & $(1.030$ & & & \\
\hline St. Dev. Of 2011 HPI in & 0.033 & 0.044 & -0.005 & & & \\
\hline 2011 ZIP code & $(0.89)$ & $(0.85)$ & $(-0.08)$ & & & \\
\hline \multirow{2}{*}{ Information only } & -0.128 & -0.077 & -0.352 & -0.060 & -0.066 & -0.024 \\
\hline & $(-0.56)$ & $(-0.24)$ & $(-0.96)$ & $(-0.60)$ & $(-0.49)$ & $(-0.14)$ \\
\hline Information only x \% drop & 0.199 & -0.041 & 1.188 & & & \\
\hline in $2008 \mathrm{ZIP}$ code HPI & $(0.29)$ & $(-0.04)$ & $(1.02)$ & & & \\
\hline \multirow{2}{*}{ Female } & 0.006 & 0.055 & 0.000 & 0.025 & 0.082 & -0.011 \\
\hline & $(0.06)$ & $(0.42)$ & $(0.00)$ & $(0.27)$ & $(0.63)$ & $(-0.07)$ \\
\hline \multirow{2}{*}{ Risk aversion } & 0.000 & 0.000 & 0.000 & 0.000 & 0.000 & 0.000 \\
\hline & $(-0.77)$ & $(1.45)$ & $(-0.87)$ & $(-0.45)$ & $(1.41)$ & $(-0.32)$ \\
\hline \multirow{2}{*}{ Age } & $-0.035+$ & 0.008 & 0.003 & $-0.035+$ & 0.006 & 0.006 \\
\hline & $(-1.78)$ & $(0.74)$ & $(0.21)$ & $(-1.80)$ & $(0.52)$ & $(.45)$ \\
\hline \multirow{2}{*}{ Age $^{2}$} & 0.000 & & & 0.000 & & \\
\hline & $(1.40)$ & & & $(1.40)$ & & \\
\hline \multirow{2}{*}{ Age $x$ risk aversion } & 0.000 & 0.000 & 0.000 & 0.000 & 0.000 & 0.000 \\
\hline & $(1.22)$ & $(-1.53)$ & $(1.17)$ & $(0.82)$ & $(-1.50)$ & $(0.58)$ \\
\hline \multirow{2}{*}{ Rents Home } & 0.049 & 0.108 & -0.081 & 0.086 & 0.191 & -0.048 \\
\hline & $(0.34)$ & $(0.57)$ & $(-0.30)$ & $(0.61)$ & $(1.03)$ & $(-0.18)$ \\
\hline Mean 2011 gas price in & 0.490 & 1.029 & 0.079 & 0.058 & 0.112 & 0.301 \\
\hline 2011 ZIP code & $(0.65)$ & $(1.02)$ & $(0.06)$ & $(0.09)$ & $(0.13)$ & $(0.27)$ \\
\hline St. Dev of 2011 gas price in & -1.269 & 2.074 & $-5.444+$ & -2.290 & 0.386 & $-6.510^{*}$ \\
\hline 2011 ZIP code & $(-0.72)$ & $(0.86)$ & $(-1.83)$ & $(-1.36)$ & $(0.17)$ & $(-2.29)$ \\
\hline \multirow{2}{*}{ Constant } & 1.467 & -0.436 & 0.135 & 2.495 & 1.373 & -0.558 \\
\hline & $(0.62)$ & $(-0.14)$ & $(0.03)$ & $(1.12)$ & $(0.46)$ & $(-0.15)$ \\
\hline Observations & 827 & 456 & 366 & 840 & 462 & 372 \\
\hline Pseudo R-squared & 0.056 & 0.085 & 0.128 & 0.052 & 0.079 & 0.118 \\
\hline
\end{tabular}

Z statistics in parentheses $=+p<0.10,{ }^{*} p<0.05,{ }^{* *} p<0.01$.

Note: We also controlled for income level, racial and ethnic groups, , number of children <18, highest school grade completed, marital status, and demographic characteristics of the individual's 2000 ZIP code (gender composition, racial composition, percentage in poverty, percentage with a college degree). See table A1 for categories of individual characteristics. 


\section{Appendix}

\section{Table A1. Michigan Consumer Survey Variable List}

\begin{tabular}{lc}
\hline Variable & Variable \\
Gender & name \\
Male or female & sex \\
Race & race \\
Categories are White (except Hispanic), Black (except Hispanic), Hispanic, Asian or & \\
Pacific Islander, and American Indian or Alaska Native & age \\
Age & \\
(years) & marry \\
Marital status & \\
Categories are married, never married, separated, divorced, and spouse lives away & \\
(including in service or in nursing home) & qincsum \\
\hline Annual Income Bracket &
\end{tabular}

Categories are increments of $\$ 5,000$ from $\$ 10,000-\$ 49,999 ; \$ 50,000-\$ 59,999$;

$\$ 60,000$ - $\$ 74,499$; increments of $\$ 25,000$ from $\$ 75,000$ - $\$ 174,999 ; \$ 175,000+$.

Respondents could also specify only that their income was above or below $\$ 50,000$.

\begin{tabular}{ll} 
Number of children under 18 in household & numkid \\
\hline Highest grade completed in school & egrade \\
\hline Language of interview & language \\
English or Spanish &
\end{tabular}

Home ownership status

homeown

Categories are owns or is buying, rent, housing is part of pay, public housing, home owned by a relative, staying temporarily in other person's home

Expectations regarding gas prices in next 5 years

gaspx1

Categories are go up, stay the same, or go down 
Table A2. Rent-versus-Own, by Age Group (1 ${ }^{\text {st }}$ alternative definition of rent-versus-own)

"Owning is without a doubt better," and "owning is probably better," are coded as 1; "renting is without a doubt better," and "renting is probably better," are coded as 0; neutral responses are dropped.)

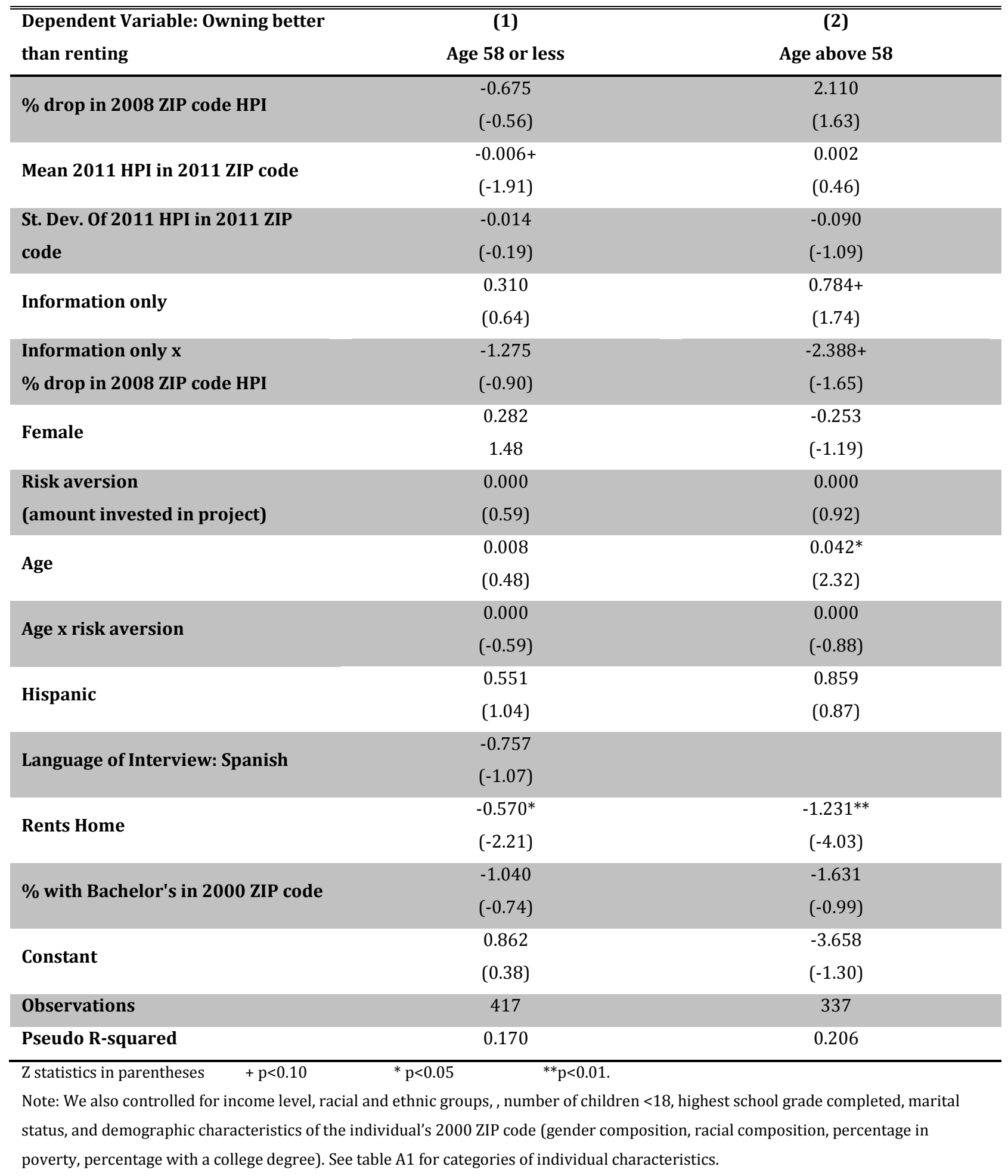


Table A3. Rent-versus-0wn, By Age Group (2nd alternative definition of rent-versus-own)

"Owning is without a doubt better" is coded as 1 ; "Owning is probably better" coded as 0 ; and all other responses are dropped.

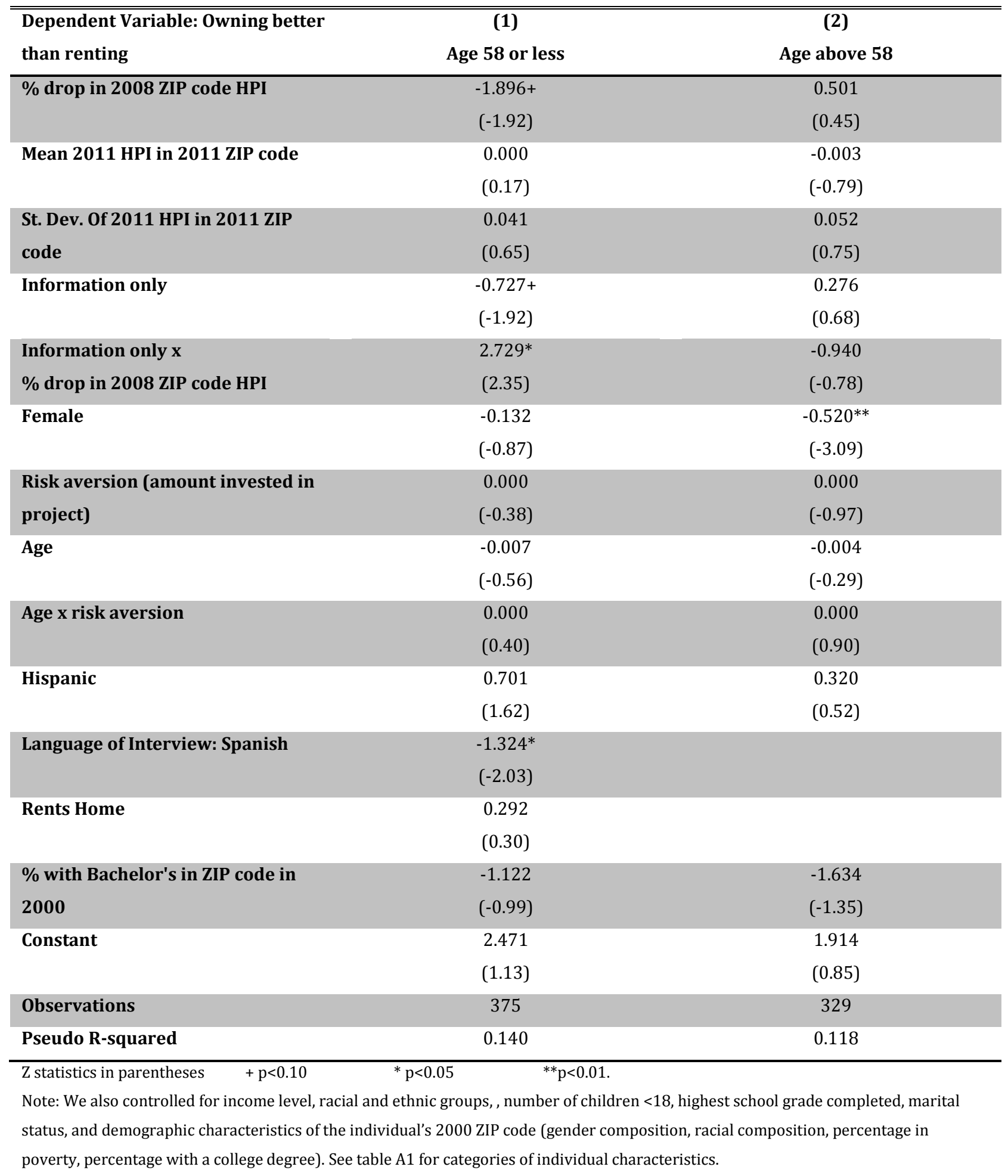


Table A4. Effect of Change in HPI on Investment Decision

\begin{tabular}{|c|c|c|c|}
\hline $\begin{array}{l}\text { Dependent variable: } \\
\text { Amount Invest in risky } \\
\text { project }\end{array}$ & (1) All ages & (2) Age $<=58$ & (3) Age $>58$ \\
\hline $\begin{array}{l}\text { \% drop in } 2008 \mathrm{ZIP} \text { code } \\
\text { HPI }\end{array}$ & $\begin{array}{l}808.9 \\
(0.70)\end{array}$ & $\begin{array}{l}1807.3 \\
(1.14)\end{array}$ & $\begin{array}{l}-392.4 \\
(-0.22)\end{array}$ \\
\hline $\begin{array}{l}\text { Mean } 2011 \text { HPI in } 2011 \\
\text { ZIP code }\end{array}$ & $\begin{array}{l}4.453 \\
(1.32)\end{array}$ & $\begin{array}{l}8.543+ \\
(1.88)\end{array}$ & $\begin{array}{l}-2.581 \\
(-0.48)\end{array}$ \\
\hline $\begin{array}{l}\text { St. Dev of } 2011 \text { HPI in } \\
2011 \text { ZIP code }\end{array}$ & $\begin{array}{l}29.36 \\
(0.40)\end{array}$ & $\begin{array}{l}104.8 \\
(1.06)\end{array}$ & $\begin{array}{l}-0.473 \\
(0.00)\end{array}$ \\
\hline Information only & $\begin{array}{l}428.7 \\
(0.98)\end{array}$ & $\begin{array}{l}509.4 \\
(0.82)\end{array}$ & $\begin{array}{l}262.6 \\
(0.39)\end{array}$ \\
\hline $\begin{array}{l}\text { Information only x \% } \\
\text { drop in } 2008 \text { ZIP code HPI }\end{array}$ & $\begin{array}{l}-658.4 \\
(-0.50)\end{array}$ & $\begin{array}{l}-843.3 \\
(-0.45)\end{array}$ & $\begin{array}{l}-87.20 \\
(-0.04)\end{array}$ \\
\hline Female & $\begin{array}{l}-273.0 \\
(-1.49)\end{array}$ & $\begin{array}{l}-419.0 \\
(-1.64)\end{array}$ & $\begin{array}{l}-113.9 \\
(-0.40)\end{array}$ \\
\hline Age & $\begin{array}{l}7.785 \\
(0.22)\end{array}$ & $\begin{array}{l}-23.26 \\
(-1.57)\end{array}$ & $\begin{array}{l}-50.31^{* *} \\
(-2.76)\end{array}$ \\
\hline Age $^{2}$ & $\begin{array}{l}-0.314 \\
(-1.02)\end{array}$ & & \\
\hline Hispanic & $\begin{array}{l}469.7 \\
(0.83)\end{array}$ & $\begin{array}{l}818.2 \\
(1.19)\end{array}$ & $\begin{array}{l}206.2 \\
(0.18)\end{array}$ \\
\hline $\begin{array}{l}\text { Language of Interview: } \\
\text { Spanish }\end{array}$ & $\begin{array}{l}-12.55 \\
(-0.01)\end{array}$ & $\begin{array}{l}-276.4 \\
(-0.28)\end{array}$ & $\begin{array}{l}-333.4 \\
(-0.13)\end{array}$ \\
\hline Rents Home & $\begin{array}{l}181.2 \\
(0.64)\end{array}$ & $\begin{array}{l}381.2 \\
(1.04)\end{array}$ & $\begin{array}{l}-122.3 \\
(-0.25)\end{array}$ \\
\hline $\begin{array}{l}\text { \% with Bachelor's in ZIP } \\
\text { code in } 2000\end{array}$ & $\begin{array}{l}-345.6 \\
(-0.26)\end{array}$ & $\begin{array}{l}1041.0 \\
(0.56)\end{array}$ & $\begin{array}{l}-1004.5 \\
(-0.48)\end{array}$ \\
\hline Constant & $\begin{array}{l}3917.3 \\
(1.60)\end{array}$ & $\begin{array}{l}671.5 \\
(0.20)\end{array}$ & $\begin{array}{l}9295.6^{*} \\
(2.50)\end{array}$ \\
\hline Observations & 907 & 473 & 434 \\
\hline R-squared & 0.084 & 0.125 & 0.100 \\
\hline
\end{tabular}

T statistics in parentheses $=+\mathrm{p}<0.10,{ }^{*} \mathrm{p}<0.05,{ }^{* *} \mathrm{p}<0.01$

Note: We also controlled for income level, racial and ethnic groups, , number of children $<18$, highest school grade completed, marital status, and demographic characteristics of the individual's 2000 ZIP code (gender composition, racial composition, percentage in poverty, percentage with a college degree). See table A1 for categories of individual characteristics. 